\title{
Effect of Ni-Mo Carbide Catalyst Formation on Furfural Hydrogenation
}

\author{
Ivan N. Shilov ${ }^{1,2}$, Andrey A. Smirnov 1,2,*, Olga A. Bulavchenko ${ }^{1,2}$ (D) and Vadim A. Yakovlev 1,2 \\ 1 Novosibirsk State University, Pirogova Str., 2, 630090 Novosibirsk, Russia; shilov@catalysis.ru (I.N.S.); \\ isizy@catalysis.ru (O.A.B.); yakovlev@catalysis.ru (V.A.Y.) \\ 2 Boreskov Institute of Catalysis SB RAS, Lavrentev Ave., 5, 630090 Novosibirsk, Russia \\ * Correspondence: asmirnov@catalysis.ru; Tel.: +7-383-32-69-652
}

Received: 22 October 2018; Accepted: 15 November 2018; Published: 19 November 2018

\begin{abstract}
High-loading Ni-Mo carbide catalysts were prepared by the modified gel-combustion method under various thermal treatment conditions. All samples were studied by X-ray diffraction (XRD) analysis, which showed that the catalysts could contain cubic and hexagonal molybdenum carbides, nickel, nickel oxide and Ni-Mo solid solutions, depending on the thermal treatment conditions. Study of catalyst activity and selectivity in the hydrogenation of furfural was carried out in a batch reactor at $150{ }^{\circ} \mathrm{C}$ and hydrogen pressure $6.0 \mathrm{MPa}$. Analysis of the reaction products showed that the highest yields of 2-methylfuran (2-MF) and furfuryl alcohol (FA) were achieved using catalysts synthesized by calcination of the nickel-molybdenum-carbon precursor at $400{ }^{\circ} \mathrm{C}$ with the following reduction in a stream of hydrogen at $600^{\circ} \mathrm{C}$. The best results for production of FA with a yield of $80 \mathrm{~mol} \%$ and 2-MF with a yield of $29 \mathrm{~mol} \%$ were observed using $\mathrm{Ni}_{6} \mathrm{MoC}-\mathrm{SiO}_{2}$ $(400 / 600)$ and $\mathrm{Ni}_{1} \mathrm{MoC}_{\mathrm{SiO}} \mathrm{SiO}_{2}(400 / 600)$ catalysts, respectively. It has been shown that the addition of nickel to the carbide molybdenum catalyst significantly increases the activity of the catalytic systems. In addition, nickel also contributes to the formation of products formed by hydrogenation of the aromatic ring tetrahydrofurfuryl alcohol (THFA) and 2-methyltetrahydrofuran (2-MTHF).
\end{abstract}

Keywords: molybdenum carbide; hydrogenation; furfural; furfuryl alcohol; 2-methylfuran

\section{Introduction}

An intensive growth of energy consumption has led to the search for new types of alternative fuel and their comprehensive study. Against the background of a decrease in the reserves of fossil hydrocarbons and a significant increase in the prices of oil-refining products, obtaining of valuable chemicals and fuel derivatives from renewable raw materials has become very popular. Furfural is a promising bio-renewable resource for processing into different derivatives [1,2]. A technology for furfural production is the hydrolysis of hemicellulose, and the annual world production nowadays amounts to about 300 thousand tons [3,4]. Hydrogenation is one of the key furfural processing methods. Using this method, many substances, particularly 2-methylfuran (2-MF) and furfuryl alcohol (FA), can be obtained.

Furfuryl alcohol is one of the most important products of furfural conversion. Approximately $65 \%$ of furfural production is processed into this chemical compound [5]. FA can be used in the foundry resin manufacturing [6] or as an advanced solvent for highly effective chemical processes of chlorination of aromatics and oxygenation of organic compounds [7]. Also, FA is used for the production of polyesters, polyurethane foams and as a chemical building block for the synthesis of some pharmaceuticals (e.g., ranitidine) and fragrances [5,8].

Another high-value derivative, which can be obtained from furfural by selective hydrogenation, is 2-methylfuran. Due to its physical properties, 2-MF can be used as a fuel with an octane number of 
$74[9,10]$ and it also could be converted to hydrocarbons of diesel fraction [11,12]. Nowadays, special attention is paid to the application of 2-methylfuran as a high-octane additive. This interest is based on the physical properties of 2-MF. In comparison with other furfural derivatives, 2-MF has a higher blending research octane number of 131. 2-MF has a low boiling point of $64{ }^{\circ} \mathrm{C}$, which makes it an attractive component of the fuel for cold-start exhaust emission test. In addition, 2-methylfuran has already been tested as a part of a mixture with EN228 gasoline. In the study, a mixture containing 10 vol.\% of 2-MF passed road tests on several vehicles with a total route length of 90 thousand kilometres. It was found that the addition of 2-MF did not have negative influence on the engine or the engine oil. Besides, the use of 2-MF as an additive leads to a fuel economy of $2 \%$ (compared to a mixture of ethanol and gasoline) [13].

A method for the industrial production of 2-MF and FA from furfural includes the use of $\mathrm{Cu}-\mathrm{Cr}$ catalysts or catalytic systems based on Pt or Pd. For example, Wojcik et al. [14] have been investigating the hydrogenation of furan compounds in the presence of $\mathrm{Ni}$ Raney and $\mathrm{Cu}-\mathrm{CrO}$ catalysts. It was found that the yield of FA using a copper-chromium oxide catalyst is $96-99 \%$ at $175{ }^{\circ} \mathrm{C}$. Further hydrogenation of $\mathrm{FA}$ over $\mathrm{Cu}-\mathrm{CrO}$ leads to the production of 2-methylfuran $(36 \%)$, pentanol $(36 \%)$, 1,5-pentanediol (14\%) and 1,2-pentanediol (14\%). A nearly 99\% yield of 2-MF can be achieved using carbon supported $\mathrm{Cu}-\mathrm{Cr}$ systems in the gas phase furfural hydrogenation $[15,16]$. However, a serious disadvantage of processes in the gaseous phase over $\mathrm{Cu}-\mathrm{Cr}$ catalysts is a rapid catalyst deactivation associated with coke formation, change in the oxidation state of the copper, and agglomeration of $\mathrm{Cu}$ particles during the reaction due to high temperature [17,18]. A typical example of such systems are $\mathrm{Cu}-\mathrm{Cr}$ catalysts investigated by Kai Yan and Aicheng Chen $[19,20]$. Authors found that $\mathrm{Cu}-\mathrm{Cr}$ oxide catalyst with the $\mathrm{Cu}^{2+} / \mathrm{Cr}^{3+}$ ratio of 2 allows furfural to be hydrogenated with conversion of $95.0 \%$ and FA yield equal to $90.1 \%$ at $\mathrm{T}=200{ }^{\circ} \mathrm{C}$, contact time of $4 \mathrm{~h}$ and $\mathrm{H}_{2}$ pressure of $6.0 \mathrm{MPa}$. At the same time, all $\mathrm{Cu}-\mathrm{Cr}$ systems are vulnerable to carbon deposition and deactivation, consequently reusing of the $\mathrm{Cu}-\mathrm{Cr}$ sample with $\mathrm{Cu}^{2+} / \mathrm{Cr}^{3+}$ ratio of 2 under the same condition leads to conversion of $83.3 \%$ and FA yield of $75.3 \%$. Moreover, $\mathrm{Cu}-\mathrm{Cr}$ systems have high toxicity and a detrimental effect on the environment. Supported noble metals also demonstrate high activity in the selective hydrogenation of furfural and its derivatives. For example, $\mathrm{Pd} / \mathrm{TiO}_{2}$ prepared by the standard wet impregnation method allows obtaining 2-MF from FA with a selectivity of $92.5 \%$ at room temperature [21]. However, this type of Pd-based catalysts also promotes polymerization reactions and the formation of THFA. Vetere et al. [22] showed a high selectivity of $\mathrm{Pt}$ supported on $\mathrm{SiO}_{2}$ in the hydrogenation of furfural to furfuryl alcohol and found that the catalytic activity can be increased by doping of $\mathrm{Pt} / \mathrm{SiO}_{2}$ with a small amount of tin. It is possible to change selectivity and activity of Pt-based systems using other supports. Like, for instance, the hydrogenation of furfural over the impregnated $5 \mathrm{wt} \% \mathrm{Pt}$ catalyst supported on $\mathrm{Al}_{2} \mathrm{O}_{3}$ results in a $46 \%$ feedstock conversion with keeping the FA selectivity at 98\% [23]. In contrast, the use of $\mathrm{Pt}(5 \mathrm{wt} \%) / \mathrm{C}$ catalyst decreases the FA selectivity to $28 \%$ and increases the furfural conversion to $94 \%$ [24]. In this way, noble metal catalysts opened wide possibilities to hydrogenate furfural. Nevertheless, $\mathrm{Pt}$ and Pd-based catalysts are less promising for the production of FA and 2-MF than $\mathrm{Cu}-\mathrm{Cr}$ systems. Furthermore, a high cost of noble metals makes exploitation of these catalytic systems less economically viable.

Alternative catalysts for hydrogenation of furfural can be nickel-molybdenum carbide systems. Previously, the catalysts based on molybdenum carbide, have already proven themselves as highly effective catalysts for bio-oil and vegetable oil hydrotreatment $[25,26]$. An important feature of these catalysts is their activity in the formation of aromatic hydrocarbons and selectivity in the hydrogenation of alcohol and carbonyl groups [27-30]. Boullosa-Eiras et al. [31] compared $\mathrm{Mo}_{2} \mathrm{C} / \mathrm{TiO}_{2}$ with $\mathrm{MoO}_{3} / \mathrm{TiO}_{2}, \mathrm{Mo}_{2} \mathrm{~N} / \mathrm{TiO}_{2}$ and $\mathrm{MoP} / \mathrm{TiO}_{2}$ catalysts in the process of phenol hydrogenation. Based on the experimental data, molybdenum carbide was identified as the most active and selective catalyst for the hydrogenation of phenol to benzene. However, the study of the catalysts' stability showed that the activity of $\mathrm{Mo}_{2} \mathrm{C} / \mathrm{TiO}_{2}$ has declined by some 10 percent after 400 min of reaction time. Authors explain this catalyst behaviour by the deposition of coke on the catalyst surface and the decrease in the 
number of active sites. Lee et al. [32] investigated the activity of molybdenum carbide during the gas phase hydrogenation of furfural. They showed that molybdenum carbide is able to hydrogenate the aldehyde $\mathrm{C}=\mathrm{O}$ group, which makes it possible to achieve $60 \%$ selectivity for 2-MF at relatively low temperatures about $150{ }^{\circ} \mathrm{C}$. It is reported that the surface of the catalyst is presented by two types of sites: carbide and metal-like ones. Carbide sites have acidic properties and participate in the furfural chemisorption. The metal-like part of the surface interacts with molecular hydrogen and leads to its dissociative adsorption. Xiong and colleagues $[29,30]$ studied $\mathrm{Mo}_{2} \mathrm{C}$ in the deoxygenation of aldehydes and alcohols. In particular, furfural and FA were used as model compounds. The dehydrogenation reactions of molecules were explored using temperature-programmed desorption, the HREELS method, and the theory of functional density. It was shown that molybdenum carbide is involved in a strong interaction with the aldehyde group of furfural, which corresponds to a high selectivity of furfural hydrogenation to 2-MF.

The reusability of the molybdenum carbide catalysts was investigated many times before. Rui Ma et al. [33] studied the process of guaiacol deoxygenation to monooxygenated phenols over activated carbon supported molybdenum carbide. They showed that similar conversion and selectivity towards the target products were achieved in three cycles of catalysts exploitation. At the same time, XRD patterns of the recovered catalysts showed negligible changes in nanoparticle sizes, thus indicating the high stability of these systems. Stability of molybdenum carbide under more aggressive conditions was studied by Dhandapani et al. [34]. They investigated simultaneous hydrogenation of cumene, hydrodesulphurization of dibenzothiophene, and hydrodeoxygenation of benzofuran over a $\beta-\mathrm{Mo}_{2} \mathrm{C}$ catalyst. Authors found that $\mathrm{Mo}_{2} \mathrm{C}$ had high hydrogenation activity for sulphur concentrations up to $30 \pm 60$ ppm S during $80 \mathrm{~h}$, while the Pt catalyst deactivated immediately even with a small amount of sulphur in the feedstock. In another research, carbon supported molybdenum carbide doped by $\mathrm{Ni}$ was applied for selective hydrogenation of lignin [35]. According to this paper, the $\mathrm{Ni}-\mathrm{Mo}_{2} \mathrm{C} / \mathrm{C}$ catalyst was tested with an initial $\mathrm{H}_{2}$ pressure of $2 \mathrm{MPa}$ and $250{ }^{\circ} \mathrm{C}$ for $2 \mathrm{~h}$ in a mixture of lignin and isopropanol. After each using, the sample was removed from reactor and separated from solid residual by a magnet. The yields of liquid product were almost unchanged during five runs and remained at around $60 \%$. Herewith, the $\mathrm{Ni}$ and Mo contents in the liquid reaction phase were 0.75 and $17.8 \mu \mathrm{g} \cdot \mathrm{L}^{-1}$, respectively. All these aspects also indicate good stability and reusability of Ni-Mo carbide catalysts. An important factor is that there is a method for regeneration of carbide catalysts by sequential oxidization of cemented metal carbide at a high temperature above $600{ }^{\circ} \mathrm{C}$ and carbonization with a gas mixture of methane and hydrogen [36].

Based on the reasons mentioned here, it is possible to claim that furfural conversion has an importance for modern industry and green chemistry. To reduce the impact on the environment, it is necessary to change the catalytic systems for furfural hydrogenation, as one of the most demanded processes. To avoid Cr-containing catalysts, molybdenum carbide could be suggested as an efficient, stable and environment friendly system for furfural hydrogenation.

In our previous research, the effect of bimetallic Ni-Mo carbide catalysts on the hydrogenation of anisole and ethyl caprate was studied [37]. It was shown that the presence of the $\mathrm{Mo}_{2} \mathrm{C}$ phase in the catalyst promotes the removal of the methoxy group from anisole without aromatic ring hydrogenation. At the same time, the addition of nickel in the catalyst significantly increases its activity and resistance to coke formation. Thus, Ni-Mo carbides have a high potential for hydrogenation of aldehydes and alcohols. An important application of these catalysts can be hydrogenation of furfural to FA and 2-MF. In the present work, we studied the effect of heat treatment of Ni-Mo carbide on its composition and catalytic properties in furfural hydrogenation to produce FA and 2-MF. It is important to note that Ni-modified molybdenum carbides were studied for the first time in the process of furfural hydrogenation. The catalysts are multicomponent systems resulting from the heat treatment of carbide precursors at 600 or $700{ }^{\circ} \mathrm{C}$ in argon or from the sequential treatment in an inert gas (Ar) and hydrogen at 400 and $600{ }^{\circ} \mathrm{C}$, respectively. The X-ray diffraction (XRD) was used to determine the composition of the active phase in the catalysts. In addition, samples are characterized by transmission electron 
microscopy (TEM), X-ray photoelectron spectroscopy (XPS), nitrogen porosimetry and CO pulse chemisorption measurements. The carbon deposition during furfural hydrogenation is also studied by CHNS analysis of catalysts before and after the reaction.

\section{Results and Discussion}

\subsection{Catalytic Performance of Carbide Catalysts In furfural Hydrogenation Process}

On the first step, the influence of the stabilizing $\mathrm{SiO}_{2}$ additive on a sample of molybdenum carbide $\mathrm{MoC}$ calcined at $700{ }^{\circ} \mathrm{C}$ was studied. It was found that molybdenum carbide synthesized without ethyl silicate virtually does not catalyse furfural hydrogenation under the chosen conditions. The reaction was carried out for $3.5 \mathrm{~h}$, but the concentration of furfural did not change. However, the introduction of silicon dioxide into the catalyst composition increases the activity and leads to the formation of target products, FA and 2-MF. At the same time, the $\mathrm{MoC}-\mathrm{SiO}_{2}(700)$ catalyst promotes the formation of the condensation product of furfural and isopropyl alcohol, furfuryl-hydroxyl-isopropyl ether (FHIE). This compound probably appears before hydrogen introduction into the reactor during heating. Its concentration remains constant throughout the entire process (about $10 \mathrm{~mol} \%$ ). This indicates the equilibrium between furfural, isopropanol and their condensation product. Earlier, the formation of a similar product over bimetallic Ni-Cu catalysts was already observed by Khromova et al. [38], but the reasons for implementation of this reaction pathway were not discussed. The effect of acidic catalysts on the acetaldehyde and ethanol condensation was studied by Capeletti at al. [39]. Authors note the high activity of acidic catalytic systems in the condensation of a monohydric alcohol with the aldehyde to form a substance similar to FHIE. Thus, the formation of the furfural and isopropyl alcohol condensation product over molybdenum carbide can be explained by the acidity of its active sites, reported by Bennett et al. in [40]. Based on the reaction products analysis for sample $\mathrm{MoC}-\mathrm{SiO}_{2}$ (700), a process scheme shown in Figure 1 was suggested. It includes the pathway for sequential hydrogenation of furfural to FA and 2-MF and the formation of FHIE.

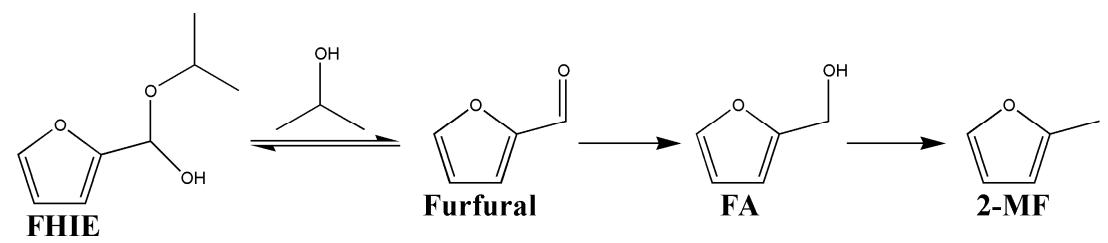

Figure 1. Scheme of furfural hydrogenation over calcined catalyst $\mathrm{MoC}-\mathrm{SiO}_{2}(700)$ at $\mathrm{T}=150{ }^{\circ} \mathrm{C}$, $\mathrm{P}=6.0 \mathrm{MPa}, \mathrm{m}_{\mathrm{cat}}=1.000 \mathrm{~g}$, and furfural/isopropanol molar ratio equal to 0.033 .

Nevertheless, silica-stabilized molybdenum carbide showed a rather low activity. In the instance using a sample of $\mathrm{MoC}^{-\mathrm{SiO}_{2}}$ (700) for $3.5 \mathrm{~h}$, the FA yield was $16 \%$, and the yield of 2-MF was only $3 \%$. Therefore, nickel-doped catalysts that have higher activity in the furfural hydrogenation reaction have been studied. The results obtained over nickel-containing catalysts synthesized under different temperature treatment processes are presented in Table 1.

Table 1. The results of furfural hydrogenation over Ni-Mo carbide systems synthesized under various heat treatment conditions. Reaction conditions: $\mathrm{T}=150{ }^{\circ} \mathrm{C}, \mathrm{P}=6.0 \mathrm{MPa}, \mathrm{m}_{\text {cat }}=1.000 \mathrm{~g}$, and furfural/isopropanol molar ratio equal to 0.033 .

\begin{tabular}{|c|c|c|c|c|c|c|c|}
\hline \multirow{2}{*}{ Entry } & \multirow{2}{*}{ Catalyst } & \multirow{2}{*}{ Contact Time, Min } & \multirow{2}{*}{ Furfural Conversion, $\mathrm{mol} \%$} & \multicolumn{4}{|c|}{ Yields of Reaction Products, mol \% } \\
\hline & & & & FA & 2-MF & THFA & 2-MTHF \\
\hline 1 & $\mathrm{Ni}_{0.5} \mathrm{MoC}-\mathrm{SiO}_{2}(600)$ & 180 & 58 & 54 & 4 & - & - \\
\hline 2 & $\mathrm{Ni}_{1} \mathrm{MoC}-\mathrm{SiO}_{2}(600)$ & 60 & 92 & 70 & 9 & 12 & 1 \\
\hline 3 & $\mathrm{Ni}_{2} \mathrm{MoC}-\mathrm{SiO}_{2}(600)$ & 20 & 79 & 40 & 15 & 22 & 2 \\
\hline 4 & $\mathrm{Ni}_{6} \mathrm{MoC}-\mathrm{SiO}_{2}(600)$ & 40 & 66 & 34 & 7 & 23 & 2 \\
\hline 5 & $\mathrm{Ni}_{0.5} \mathrm{MoC}-\mathrm{SiO}_{2}(700)$ & 140 & 95 & 67 & 15 & 12 & 1 \\
\hline 6 & $\mathrm{Ni}_{1} \mathrm{MoC}-\mathrm{SiO}_{2}(700)$ & 80 & 85 & 56 & 16 & 11 & 2 \\
\hline 7 & $\mathrm{Ni}_{2} \mathrm{MoC}-\mathrm{SiO}_{2}(700)$ & 30 & 86 & 58 & 6 & 20 & 2 \\
\hline
\end{tabular}


Table 1. Cont.

\begin{tabular}{|c|c|c|c|c|c|c|c|}
\hline \multirow{2}{*}{ Entry } & \multirow{2}{*}{ Catalyst } & \multirow{2}{*}{ Contact Time, Min } & \multirow{2}{*}{ Furfural Conversion, mol \% } & \multicolumn{4}{|c|}{ Yields of Reaction Products, mol \% } \\
\hline & & & & FA & 2-MF & THFA & 2-MTHF \\
\hline 8 & $\mathrm{Ni}_{6} \mathrm{MoC}-\mathrm{SiO}_{2}(700)$ & 20 & 89 & 41 & 10 & 30 & 2 \\
\hline 9 & $\mathrm{Ni}_{0.5} \mathrm{MoC}-\mathrm{SiO}_{2}(400 / 600)$ & 210 & 69 & 55 & 14 & - & - \\
\hline 10 & $\mathrm{Ni}_{1} \mathrm{MoC}-\mathrm{SiO}_{2}(400 / 600)$ & 210 & 91 & 60 & 29 & 2 & - \\
\hline 11 & $\mathrm{Ni}_{2} \mathrm{MoC}-\mathrm{SiO}_{2}(400 / 600)$ & 140 & 82 & 71 & 7 & 4 & - \\
\hline 12 & $\mathrm{Ni}_{4} \mathrm{MoC}-\mathrm{SiO}_{2}(400 / 600)$ & 140 & 95 & 76 & 5 & 14 & - \\
\hline 13 & $\mathrm{Ni}_{6} \mathrm{MoC}-\mathrm{SiO}_{2}(400 / 600)$ & 80 & 94 & 80 & 4 & 9 & 1 \\
\hline
\end{tabular}

For the majority of Ni-Mo catalysts, a rapid furfural conversion was observed. The main products of furfural hydrogenation were furfuryl alcohol (FA), tetrahydrofurfuryl alcohol (THFA), 2-methylfuran (2-MF), and 2-methyltetrahydrofuran (2-MTHF). The weak formation of FHIE was detected; its total amount did not exceed $4 \mathrm{~mol} \%$ and was not taken into account. The formation of hydrogenated furan ring products (THFA and 2-MTHF) was observed over all calcined catalysts and over reduced $\mathrm{Ni}_{x} \mathrm{MoC}-\mathrm{SiO}_{2}(400 / 600)$ systems with the atomic ratio with $\mathrm{x} \geq 2$. The accumulation of THFA and 2-MTHF was followed by a decrease in the FA and 2-MF concentration. Thus, for most catalysts, the target product yields achieved a certain maximum, after which they decreased. Table 1 demonstrates the yields of main products and the corresponding contact times and feedstock conversion values. From the data presented, it is clear that the nickel addition significantly increases the total activity of carbide catalysts. In this instance, the $95 \%$ conversion can be achieved in $140 \mathrm{~min}$ using the calcined at $700{ }^{\circ} \mathrm{C}$ catalyst with a minimal nickel content, $\mathrm{Ni}_{0.5} \mathrm{MoC}-\mathrm{SiO}_{2}$ (700). At the same time, $\mathrm{MoC}-\mathrm{SiO}_{2}$ (700) converts only $19 \%$ of furfural in $3.5 \mathrm{~h}$ under the applied conditions. In addition, Table 1 shows that the calcination regime of catalysts treatment significantly affects the maximal yields of FA and 2-MF. To optimize the thermal treatment conditions for Ni-Mo carbide catalysts, the dependences of FA and 2-MF maximal yields on the relative atomic ratio $\mathrm{x}=\mathrm{Ni} / \mathrm{Mo}$ were plotted point by point and analysed (Figure 2).

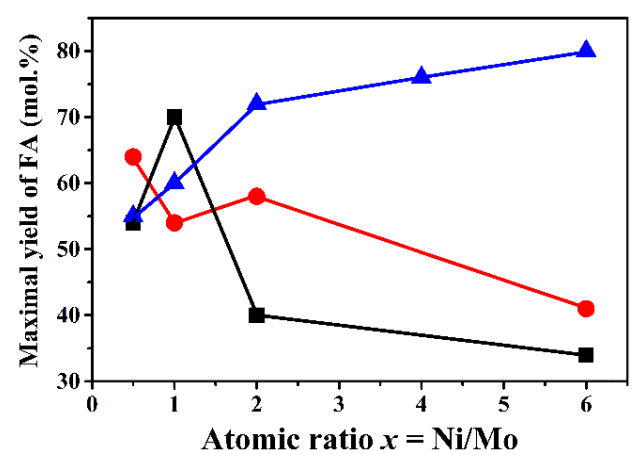

(a)

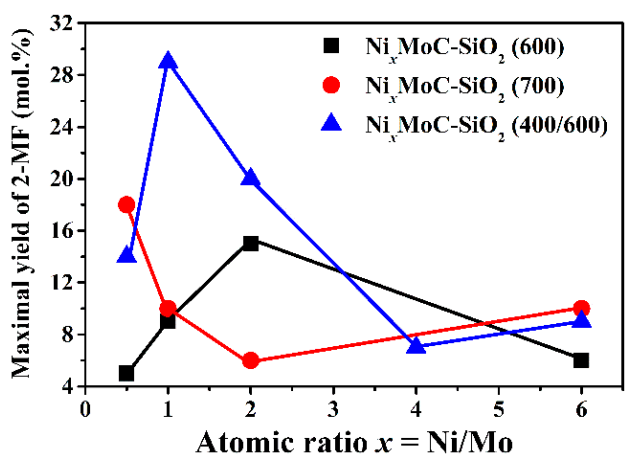

(b)

Figure 2. A comparison of FA (a) and 2-MF (b) yields for the catalysts obtained under different temperature treatment regimes. Conditions of furfural hydrogenation: $\mathrm{T}=150{ }^{\circ} \mathrm{C}, \mathrm{P}=6.0 \mathrm{MPa}$, $\mathrm{m}_{\mathrm{cat}}=1.000 \mathrm{~g}$, and furfural/isopropanol molar ratio equal to 0.033 .

The graphs in Figure 2 demonstrate that the catalysts with $x>0.5$ obtained without the reduction stage have lower yields of the target products than the reduced systems. The maximal yield of FA fixed for the calcined catalyst $\mathrm{Ni}_{1} \mathrm{MoC}-\mathrm{SiO}_{2}(600)$ is $70 \mathrm{~mol} \%$, while the system $\mathrm{Ni}_{6} \mathrm{MoC}-\mathrm{SiO}_{2}(400 / 600)$ gives the yield of FA equal to $80 \mathrm{~mol} \%$. The same situation was observed for 2-MF, which can be obtained using the catalyst $\mathrm{Ni}_{1} \mathrm{MoC}-\mathrm{SiO}_{2}(400 / 600)$ with the yield of $30 \mathrm{~mol} \%$, whereas unreduced catalysts are able to hydrogenate furfural to 2-MF with the yield only of $18 \mathrm{~mol} \%$. In addition, the $\mathrm{Ni}_{x} \mathrm{MoC}-\mathrm{SiO}_{2}(400 / 600)$ series is characterized by a monotonic increase in the FA yield with a growth in the nickel content. This feature indicates the possibility of FA production by using the Ni-Mo catalysts with high nickel content. Probably, this behaviour of the catalytic properties of unreduced systems is due to the difference in the composition of the active component. Based on these 
reasons, the catalysts obtained by calcination and subsequent reduction were recognized as the most promising in the hydrogenation of furfural to 2-MF and FA. Therefore, they were studied in more detail in the catalyst characterization part.

\subsection{Phase Composition of $\mathrm{Ni}-\mathrm{Mo}$ Carbide Catalysts}

All the catalysts considered in this paper were studied by X-ray diffraction analysis immediately after synthesis. Figure 3 shows the $\mathrm{X}$-ray diffraction pattern of the $\mathrm{MoC}-\mathrm{SiO}_{2}$ catalyst calcined at $700{ }^{\circ} \mathrm{C}$ in an argon flow. It exhibits broad reflections of cubic molybdenum carbide fcc- $\mathrm{MoC}_{1-x}$ and narrow low-intensity peaks of hexagonal form hcp- $\mathrm{Mo}_{2} \mathrm{C}$. The diffraction pattern of fcc- $\mathrm{MoC}_{1-x}$ slightly differs from the reference data: the peaks are anisotropically broadened and slightly shifted. This behavior may be connected with the crystallites shape or the presence of stacking faults. The average crystallite size for fcc-MoC $1-x$ was estimated from the 111 reflection to be about $40 \AA$.

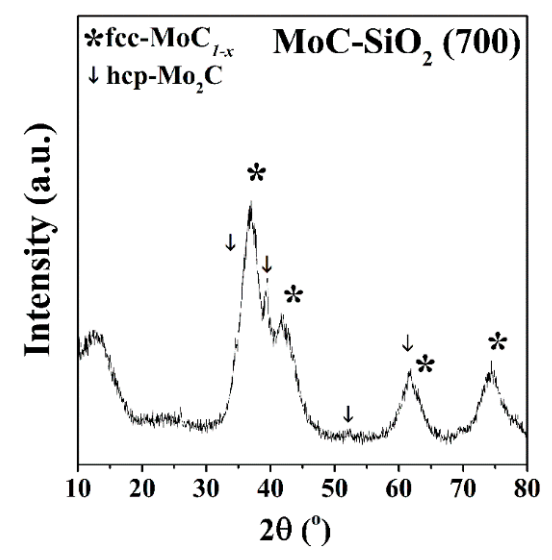

Figure 3. XRD pattern of the calcined $\mathrm{MoC}-\mathrm{SiO}_{2}(700)$ catalyst.

X-ray analysis demonstrates that the calcination conditions of nickel-molybdenum-carbon precursors have a critical effect on the formation of phases. Thus, for samples obtained by calcination in an inert atmosphere at $600{ }^{\circ} \mathrm{C}$, broad peaks corresponding to $\mathrm{NiO}$ and $\mathrm{Ni}$ reflections are observed, but there are no reflections of molybdenum-containing phases (Figure 4).

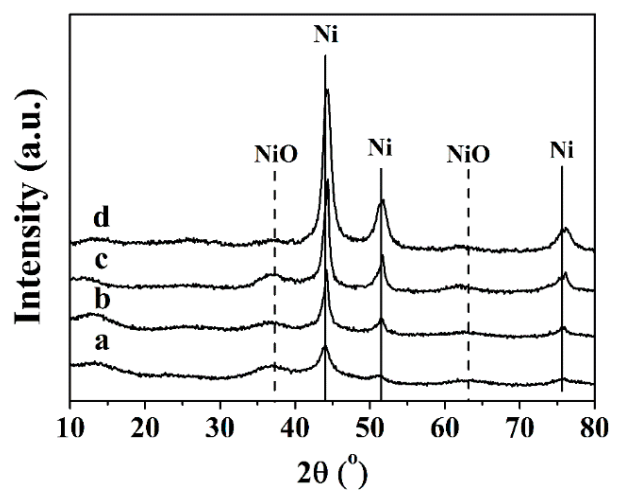

Figure 4. XRD patterns of the calcined catalysts: (a) $\mathrm{Ni}_{0.5} \mathrm{MoC}-\mathrm{SiO}_{2}$ (600); (b) $\mathrm{Ni}_{1} \mathrm{MoC}-\mathrm{SiO}_{2}(600)$; (c) $\mathrm{Ni}_{2} \mathrm{MoC}-\mathrm{SiO}_{2}$ (600); (d) $\mathrm{Ni}_{6} \mathrm{MoC}-\mathrm{SiO}_{2}$ (600).

The absence of molybdenum reflections on the X-ray patterns can be explained by the formation of highly dispersed phases or amorphous carbide forms that are not visible by XRD. In particular, the formation of highly dispersed carbide forms was reported by Vitale et al. [41]. The presence of broadened peaks in molybdenum carbide synthesized at low temperatures was reported in their work. Table 2 lists the phase ratios and average crystallite sizes determined by the Rietveld method for the $\mathrm{Ni}_{x} \mathrm{MoC}-\mathrm{SiO}_{2}(600)$ series. 
Table 2. Phase composition and average crystallite sizes for calcined $\mathrm{Ni}_{x} \mathrm{MoC}-\mathrm{SiO}_{2}(600)$ catalysts.

\begin{tabular}{|c|c|c|c|c|}
\hline Catalyst & Ni Content, wt \% & $\begin{array}{c}\text { Average Crystallite Size of } \\
\mathrm{Ni}, \AA\end{array}$ & Ni Content, wt \% & $\begin{array}{c}\text { Average Crystallite Size of } \\
\text { NiO, } \AA\end{array}$ \\
\hline $\mathrm{Ni}_{0.5} \mathrm{MoC}-\mathrm{SiO}_{2}(600)$ & 25 & 100 & 75 & 35 \\
\hline $\mathrm{Ni}_{1} \mathrm{MoC}-\mathrm{SiO}_{2}(600)$ & 40 & 115 & 60 & 25 \\
\hline $\mathrm{Ni}_{2} \mathrm{MoC}-\mathrm{SiO}_{2}(600)$ & 40 & 130 & 60 & 27 \\
\hline $\mathrm{Ni}_{6} \mathrm{MoC}-\mathrm{SiO}_{2}(600)$ & 88 & 85 & 12 & 45 \\
\hline
\end{tabular}

Thus, the formation of carbide phases that can be observed by XRD does not occur under calcination conditions at $600{ }^{\circ} \mathrm{C}$. However, for samples calcined at $700{ }^{\circ} \mathrm{C}$, the diffraction pattern changes significantly (Figure 5).

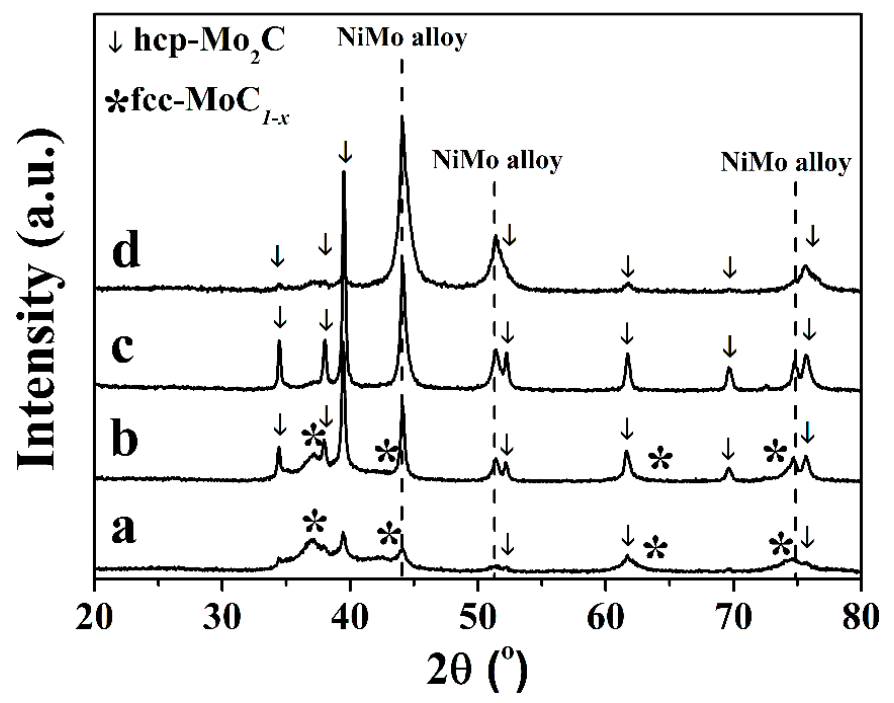

Figure 5. XRD patterns of the calcined catalysts: (a) $\mathrm{Ni}_{0.5} \mathrm{MoC}-\mathrm{SiO}_{2}$ (700); (b) $\mathrm{Ni}_{1} \mathrm{MoC}-\mathrm{SiO}_{2}$ (700); (c) $\mathrm{Ni}_{2} \mathrm{MoC}-\mathrm{SiO}_{2}(700) ;\left(\right.$ d) $\mathrm{Ni}_{6} \mathrm{MoC}-\mathrm{SiO}_{2}(700)$.

All the samples calcined at $700{ }^{\circ} \mathrm{C}$ have reflections of hcp- $\mathrm{Mo}_{2} \mathrm{C}$ and nickel-molybdenum alloy Ni-Mo. Furthermore, there are wide peaks in the angular range of $2 \theta=35-40^{\circ}$ and $40-45^{\circ}$, which apparently belong to the fcc- $\mathrm{MoC}_{1-x}$ phase. In the $\mathrm{Ni}_{x} \mathrm{MoC}-\mathrm{SiO}_{2}(700)$ series, the reflections of the cubic form are broadened and shifted also for $\mathrm{MoC}-\mathrm{SiO}_{2}(700)$. X-ray diffraction patterns of the catalysts differ in relative intensity, which corresponds to different phase ratios (Table 3).

Table 3. Phase composition of the calcined $\mathrm{Ni}_{x} \mathrm{MoC}-\mathrm{SiO}_{2}(700)$ catalysts.

\begin{tabular}{|c|c|c|c|c|}
\hline Catalyst & Phase & Content of Phase, wt \% & $\begin{array}{c}\text { Average Crystallite } \\
\text { Size, } \AA\end{array}$ & $\begin{array}{l}\text { Lattice Parameter of } \\
\text { Ni-Mo alloy, } \AA\end{array}$ \\
\hline \multirow{3}{*}{$\mathrm{Ni}_{0.5} \mathrm{MoC}-\mathrm{SiO}_{2}(700)$} & hcp- $\mathrm{Mo}_{2} \mathrm{C}$ & 23 & 160 & \\
\hline & fcc $-\mathrm{MoC}_{1-x}$ & 49 & - & \\
\hline & $\mathrm{Ni}_{0.91} \mathrm{Mo}_{0.09}$ & 28 & 150 & 3.559 \\
\hline \multirow{3}{*}{$\mathrm{Ni}_{1} \mathrm{MoC}-\mathrm{SiO}_{2}(700)$} & hcp- $-\mathrm{Mo}_{2} \mathrm{C}$ & 30 & 400 & \\
\hline & fcc-MoC $1-x$ & 34 & - & \\
\hline & $\mathrm{Ni}_{0.92} \mathrm{Mo}_{0.08}$ & 36 & 350 & 3.558 \\
\hline \multirow{3}{*}{$\mathrm{Ni}_{2} \mathrm{MoC}-\mathrm{SiO}_{2}(700)$} & hcp- $-\mathrm{Mo}_{2} \mathrm{C}$ & 29 & 630 & \\
\hline & fcc-MoC $1-x$ & 8 & - & \\
\hline & $\mathrm{Ni}_{0.92} \mathrm{Mo}_{0.08}$ & 63 & 220 & 3.556 \\
\hline \multirow{3}{*}{$\mathrm{Ni}_{6} \mathrm{MoC}-\mathrm{SiO}_{2}(700)$} & hcp- $-\mathrm{Mo}_{2} \mathrm{C}$ & 4 & 250 & \\
\hline & $\mathrm{fcc} \mathrm{MoC}_{1-x}$ & 19 & - & \\
\hline & $\mathrm{Ni}_{0.93} \mathrm{Mo}_{0.07}$ & 77 & 130 & 3.554 \\
\hline
\end{tabular}

As follows from Table 3, the largest content of Ni-Mo alloy is found in the $\mathrm{Ni}_{6} \mathrm{MoC}-\mathrm{SiO}_{2}(700)$ sample, which corresponds to the initial loading. When the nickel content decreases, the amount 
of Ni-Mo alloy decreases too. The maximum amount of fcc-MoC $\mathrm{M}_{1-x}$ was found in the catalyst $\mathrm{Ni}_{0.5} \mathrm{MoC}-\mathrm{SiO}_{2}$ (700). At the same time, the quantity of the cubic form decreases with an increase in the total Ni concentration. These dependences indicate a direct effect of the nickel content on the amount of carbide phase. Probably, nickel participates in the decomposition of the complexing agent and promotes carbon conversion to the gaseous products. Another way is also possible, in which molybdenum forms a more thermodynamically stable phase of Ni-Mo alloy without carbides formation. The lattice parameter for the Ni-Mo alloy is in the range of 3.554-3.559 $\AA$, while that for pure nickel is equal to $3.535 \AA$ (JCPDS card no. 4-850). Based on the calibration (see the Supplementary Material, Figure S1), the composition of the nickel-molybdenum alloy was determined for each catalyst. The nickel content in solid solutions was in the range of $91-93 \%$.

Catalysts prepared by calcination in an inert atmosphere with the following reduction under hydrogen flow contain hcp- $\mathrm{Mo}_{2} \mathrm{C}$ and fcc- $-\mathrm{MoC}_{1-x}$ phases and Ni-Mo alloy. In addition, peaks of the mixed molybdenum and nickel nitride $\mathrm{Mo}_{3} \mathrm{Ni}_{2} \mathrm{~N}$ were observed on the diffraction patterns. Earlier, the presence of these peaks had already been observed [37] and they were interpreted as reflections from the $\mathrm{Mo}_{3} \mathrm{CNi}_{2}$ phase. Figure 6 shows the $\mathrm{X}$-ray diffraction patterns of the catalysts of $\mathrm{Ni}_{x} \mathrm{MoC}-\mathrm{SiO}_{2}$ $(400 / 600)$ series.

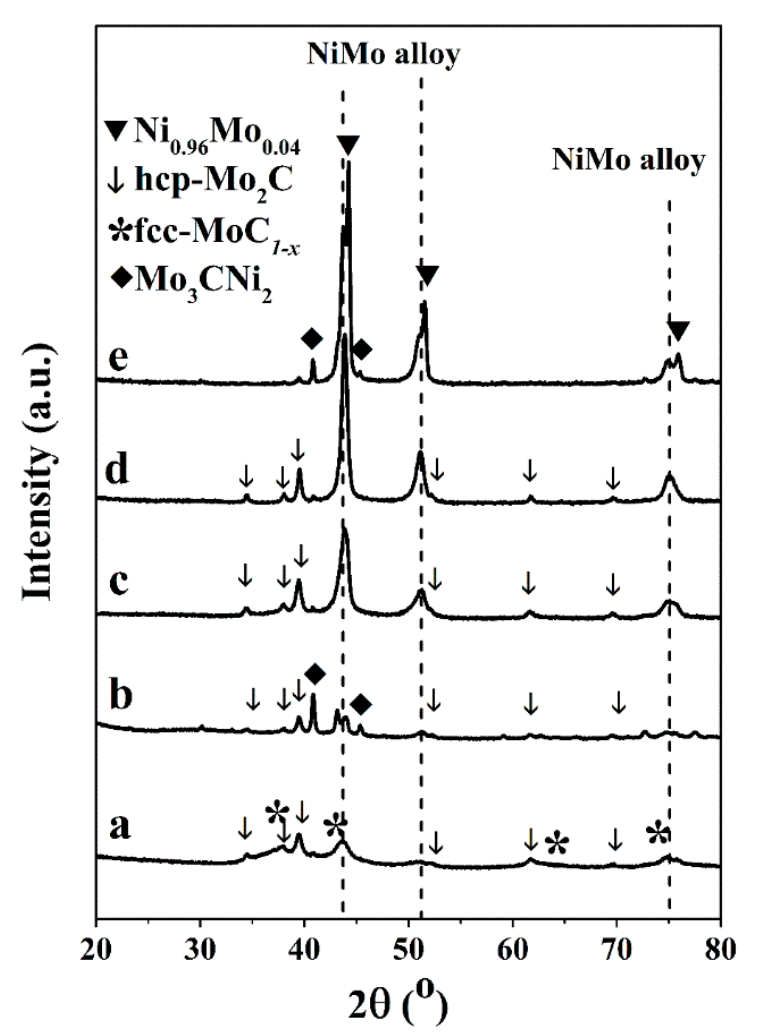

Figure 6. XRD patterns of the calcined and reduced catalysts: (a) $\mathrm{Ni}_{0.5} \mathrm{MoC}_{-} \mathrm{SiO}_{2}(400 / 600)$; (b) $\mathrm{Ni}_{1} \mathrm{MoC}-\mathrm{SiO}_{2}(400 / 600)$; (c) $\mathrm{Ni}_{2} \mathrm{MoC}_{2}-\mathrm{SiO}_{2}(400 / 600)$; (d) $\mathrm{Ni}_{4} \mathrm{MoC}-\mathrm{SiO}_{2}(400 / 600)$; (e) $\mathrm{Ni}_{6} \mathrm{MoC}_{2} \mathrm{SiO}_{2}$ (400/600).

A special feature of the system is the formation of two solid solutions $\mathrm{Ni}_{0.86} \mathrm{Mo}_{0.14}$ and $\mathrm{Ni}_{0.95} \mathrm{Mo}_{0.05}$ for $\mathrm{Ni}_{6} \mathrm{MoC}_{-} \mathrm{SiO}_{2}(400 / 600)$ catalyst. There are wide peaks in the angular range of $2 \theta=35-40^{\circ}$ and $40-45^{\circ}$ in the sample $\mathrm{Ni}_{0.5} \mathrm{MoC}-\mathrm{SiO}_{2}(400 / 600)$. They probably belong to the fcc-MoC $1-x$. It follows from the X-ray diffraction pattern that nickel addition into reduced catalytic systems increases the content of nickel-molybdenum alloy. In particular, the largest content of the Ni-Mo solution equal to $96 \mathrm{wt} \%$ is found in the $\mathrm{Ni}_{6} \mathrm{MoC}-\mathrm{SiO}_{2}(400 / 600)$ sample. The least amount of the alloy is detected in the $\mathrm{Ni}_{0.5} \mathrm{MoC}_{-} \mathrm{SiO}_{2}(400 / 600)$ catalyst and reaches $28 \mathrm{wt} \%$. More detailed information about the phase content, average crystallite sizes, and lattice parameters is listed in Table 4. 
Table 4. Phase composition of the calcined and reduced $\mathrm{Ni}_{x} \mathrm{MoC}-\mathrm{SiO}_{2}(400 / 600)$ catalysts.

\begin{tabular}{|c|c|c|c|c|}
\hline Catalyst & Phase & Content of Phase, wt \% & $\begin{array}{c}\text { Average Crystallite } \\
\text { Size, } \AA\end{array}$ & $\begin{array}{c}\text { Lattice Parameter of } \\
\text { Ni-Mo alloy, } \AA\end{array}$ \\
\hline \multirow{4}{*}{$\begin{array}{c}\mathrm{Ni}_{0.5} \mathrm{MoC}-\mathrm{SiO}_{2} \\
(400 / 600)\end{array}$} & hcp- $-\mathrm{Mo}_{2} \mathrm{C}$ & 17 & - & \multirow{4}{*}{3.586} \\
\hline & fcc-MoC $1-x$ & 51 & - & \\
\hline & $\mathrm{Mo}_{3} \mathrm{CNi}_{2}$ & 4 & - & \\
\hline & $\mathrm{Ni}_{0.84} \mathrm{Mo}_{0.16}$ & 28 & 70 & \\
\hline \multirow{4}{*}{$\begin{array}{c}\mathrm{Ni}_{1} \mathrm{MoC}-\mathrm{SiO}_{2} \\
(400 / 600)\end{array}$} & hcp- $-\mathrm{Mo}_{2} \mathrm{C}$ & 17 & 220 & \multirow{4}{*}{3.573} \\
\hline & fcc-MoC $1-x$ & 0 & - & \\
\hline & $\mathrm{Mo}_{3} \mathrm{CNi}_{2}$ & 41 & 350 & \\
\hline & $\mathrm{Ni}_{0.88} \mathrm{Mo}_{0.12}$ & 42 & 160 & \\
\hline \multirow{4}{*}{$\begin{array}{c}\mathrm{Ni}_{2} \mathrm{MoC}-\mathrm{SiO}_{2} \\
(400 / 600)\end{array}$} & hcp- $-\mathrm{Mo}_{2} \mathrm{C}$ & 14 & 170 & \multirow{4}{*}{3.577} \\
\hline & fcc-MoC ${ }_{1-x}$ & 0 & - & \\
\hline & $\mathrm{Mo}_{3} \mathrm{CNi}_{2}$ & 2 & - & \\
\hline & $\mathrm{Ni}_{0.87} \mathrm{Mo}_{0.13}$ & 84 & 110 & \\
\hline \multirow{4}{*}{$\begin{array}{c}\mathrm{Ni}_{4} \mathrm{MoC}_{-} \mathrm{SiO}_{2} \\
(400 / 600)\end{array}$} & hcp- $-\mathrm{Mo}_{2} \mathrm{C}$ & 8 & 220 & \multirow{4}{*}{3.576} \\
\hline & $\mathrm{fcc}-\mathrm{MoC}_{1-x}$ & 0 & - & \\
\hline & $\mathrm{Mo}_{3} \mathrm{CNi}_{2}$ & 2 & - & \\
\hline & $\mathrm{Ni}_{0.87} \mathrm{Mo}_{0.13}$ & 90 & 160 & \\
\hline \multirow{5}{*}{$\begin{array}{c}\mathrm{Ni}_{6} \mathrm{MoC}-\mathrm{SiO}_{2} \\
(400 / 600)\end{array}$} & hcp- $-\mathrm{Mo}_{2} \mathrm{C}$ & 1 & - & \multirow{5}{*}{$\begin{array}{l}3.580 \\
3.545\end{array}$} \\
\hline & fcc-MoC $\mathrm{M}_{1-x}$ & 0 & - & \\
\hline & $\mathrm{Mo}_{3} \mathrm{CNi}_{2}$ & 3 & - & \\
\hline & $\mathrm{Ni}_{0.86} \mathrm{Mo}_{0.14}$ & 65 & 160 & \\
\hline & $\mathrm{Ni}_{0.95} \mathrm{Mo}_{0.05}$ & 31 & 680 & \\
\hline
\end{tabular}

Table 4 demonstrates that the lattice parameters of Ni-Mo alloys range from 3.545 to $3.586 \AA$, which correspond to a nickel content from $84 \%$ to $95 \%$. The $\mathrm{Ni}_{0.95} \mathrm{Mo}_{0.05}$ phase has a lattice parameter close to pure nickel. It happens probably due to the release of the Ni phase from the Ni-Mo solution. The average crystallite size increases with the growth of the atomic ratio $x=\mathrm{Ni} / \mathrm{Mo}$. For example, the catalyst $\mathrm{Ni}_{0.5} \mathrm{MoC}-\mathrm{SiO}_{2}(400 / 600)$ has the average crystallite size equal to $70 \AA$, whereas for $\mathrm{Ni}_{6} \mathrm{MoC}_{-} \mathrm{SiO}_{2}(400 / 600)$ this size reaches $160 \AA$ (for the $\mathrm{Ni}_{0.95} \mathrm{Mo}_{0.05}$ phase it is $680 \AA$ ). It is worth noting that the total content of carbide phases decreases during the increase in the Ni loading (Figure 7). All these data indicate that nickel contributes to the carbide phase decomposition, whereas molybdenum prevents sintering of the catalyst particles.

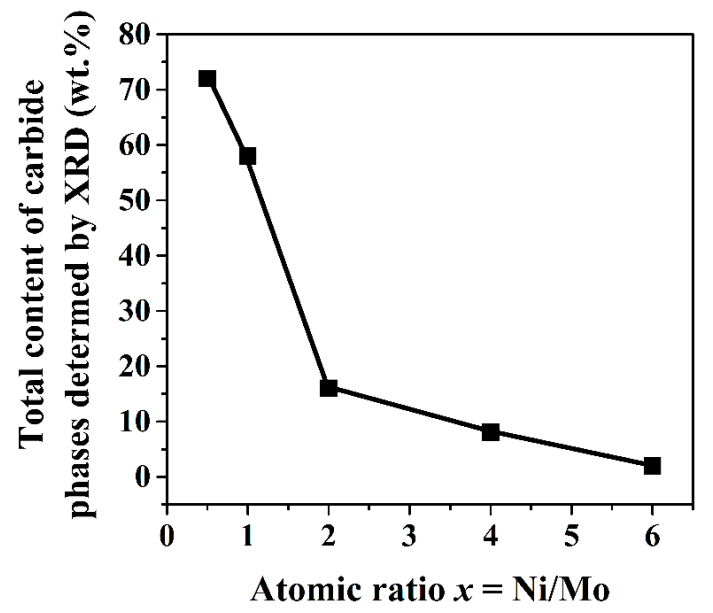

Figure 7. Dependence of the total content of carbide phases on the atomic ratio $x=\mathrm{Ni} / \mathrm{Mo}$ for the calcined and reduced $\mathrm{Ni}_{x} \mathrm{MoC}-\mathrm{SiO}_{2}(400 / 600)$ catalysts.

According to data presented, it is important to note that there are two different types of phases in the composition of reduced Ni-Mo carbon containing catalysts. The first is the carbide phase, represented by three compounds (hcp- $\mathrm{Mo}_{2} \mathrm{C}$, fcc- $-\mathrm{MoC}_{1-x}, \mathrm{Mo}_{3} \mathrm{CNi}_{2}$ ). The second is the Ni-Mo alloy 
with a high nickel content (more than $86 \mathrm{wt} \%$ ). The role of each type will be considered in the following research in the discussion of kinetics.

\subsection{Texture Characterization, Active Surface and Carbon Content of Reduced Catalysts}

In order to evaluate the quantity of active sites, the reduced samples of $\mathrm{Ni}_{x} \mathrm{MoC}-\mathrm{SiO}_{2}(400 / 600)$ catalysts were studied by $\mathrm{CO}$ chemisorption. The number of active sites was calculated from the total adsorption of carbon monoxide according to the rigorous stoichiometry of one $\mathrm{CO}$ molecule per one active site. The data obtained are shown below in Table 5 .

Table 5. The number of active sites in calcined and reduced $\mathrm{Ni}_{x} \mathrm{MoC}-\mathrm{SiO}_{2}(400 / 600)$ catalysts.

\begin{tabular}{cc}
\hline Catalyst & The Number of Active Sites Determined by CO Chemisorption, $\boldsymbol{\mu m o l} / \mathbf{g}$ \\
\hline $\mathrm{Ni}_{0.5} \mathrm{MoC}-\mathrm{SiO}_{2}$ & 90.4 \\
$\mathrm{Ni}_{1} \mathrm{MoC}-\mathrm{SiO}_{2}$ & 64.7 \\
$\mathrm{Ni}_{2} \mathrm{MoC}-\mathrm{SiO}_{2}$ & 65.5 \\
$\mathrm{Ni}_{4} \mathrm{MoC}-\mathrm{SiO}_{2}$ & 8.0 \\
$\mathrm{Ni}_{6} \mathrm{MoC}-\mathrm{SiO}_{2}$ & 11.9 \\
\hline
\end{tabular}

According to Table 5, the number of active sites decreases with increasing the nickel content. Apparently, it is connected with sintering processes, where nickel can play an important role as a component actively interacting with hydrogen at the reduction stage. On the other hand, this dependence correlates with the elemental analysis data. According to this analysis, there is a difference between total carbon content and carbon content calculated from XRD patterns (Figure 8). However, the difference is nearly absent for $\mathrm{Ni}_{4} \mathrm{MoC}-\mathrm{SiO}_{2}(400 / 600)$ and $\mathrm{Ni}_{6} \mathrm{MoC}-\mathrm{SiO}_{2}(400 / 600)$ catalysts. Remarkably, these samples are virtually free from carbide phases detected by XRD analysis, and they have the lowest number of active sites among other catalysts (see Table 5).

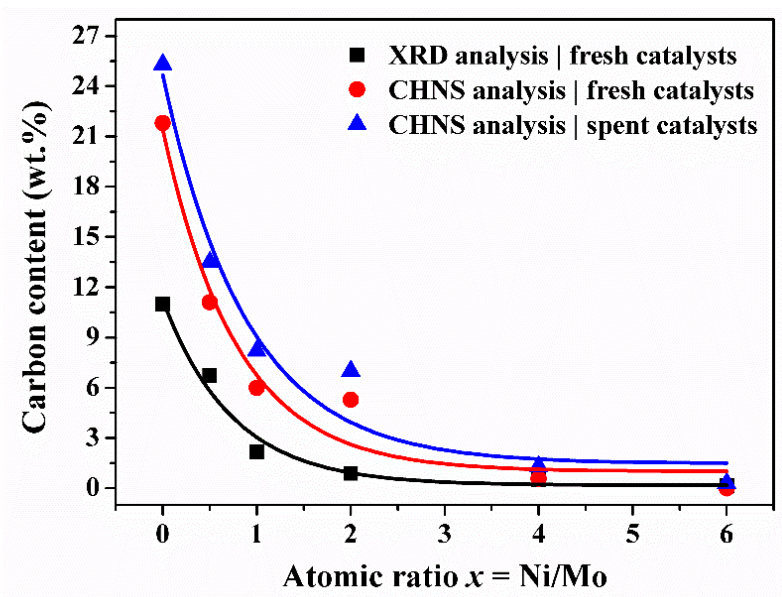

Figure 8. Relation of the total carbon content and carbon content determined from XRD data with atomic ratio $x=\mathrm{Ni} / \mathrm{Mo}$ for the calcined and reduced $\mathrm{Ni}_{x} \mathrm{MoC}-\mathrm{SiO}_{2}(400 / 600)$ catalysts and calcined $\mathrm{MoC}-\mathrm{SiO}_{2}(700)$ catalyst.

From the data presented, it is clear that the difference between total carbon amount and carbon amount included in carbide phases is equal to approximately $4 \mathrm{wt} \%$ for $\mathrm{Ni}_{x} \mathrm{MoC}-\mathrm{SiO}_{2}(400 / 600)$ with $x=0.5,1,2$; for $\mathrm{MoC}-\mathrm{SiO}_{2}$ (700) the difference is equal to $11 \mathrm{wt} \%$, and for other two catalysts the difference is absent. The existence of the discrepancy between results of elemental analysis and XRD patterns may indicate both the presence of a significant amount of highly dispersed carbide phases in the samples and the presence of amorphous free carbon. In any case, this feature indicates the complex composition of the obtained catalysts. Also, the existence of phases invisible for XRD analysis could explain high CO uptakes for $\mathrm{Ni}_{x} \mathrm{MoC}-\mathrm{SiO}_{2}(400 / 600)$ with $x<4$ in comparison with $\mathrm{Ni}_{4} \mathrm{MoC}-\mathrm{SiO}_{2}$ 
$(400 / 600)$ and $\mathrm{Ni}_{6} \mathrm{MoC}-\mathrm{SiO}_{2}(400 / 600)$. Thus, exact determination of the active sites number by $\mathrm{CO}$ chemisorption is complicated due to the lack of data about composition of X-ray amorphous phases, and information about the nature of sites for furfural adsorption and $\mathrm{CO}$ adsorption may differ. Nevertheless, the data obtained were used for calculation of the catalysts turnover frequencies (TOF), whose results and discussion are presented below. Besides, Figure 8 demonstrates the difference in the carbon content of catalyst before and after reaction. There is a tiny gap between curves belonging to fresh and spent catalysts. It could be noted that in the case of monometallic catalyst $\mathrm{MoC}-\mathrm{SiO}_{2}(700)$ the greatest increase in the carbon content was observed. With an increase in the nickel content, the amount of settled carbon in the catalyst decreases. Thus, the carbon deposition for catalyst $\mathrm{MoC}-\mathrm{SiO}_{2}(700)$ is $3.5 \%$, while for catalyst $\mathrm{Ni}_{1} \mathrm{MoC}-\mathrm{SiO}_{2}(400 / 600)$ this value does not exceed $2.2 \%$, and for system $\mathrm{Ni}_{6} \mathrm{MoC}-\mathrm{SiO}_{2}(400 / 600)$ the increase in carbon content reaches only $0.3 \%$. This feature of Ni-Mo carbide systems could be explained by their phase composition. The higher stability of bimetallic samples with high Ni content is apparently due to the fact that nickel contributes to the hydrogenation of carbon deposits with the formation of gaseous products. Herewith, carbides, prevailing in the catalysts with a low nickel content have a distinct acidity, which makes them vulnerable to coke formation. Nevertheless, Ni-containing catalysts $\mathrm{Ni}_{x} \mathrm{MoC}-\mathrm{SiO}_{2}(400 / 600)$ show high resistance to carbon deposition and could be considered as stable and promising.

Considering the above-mentioned reasons, texture characteristics of catalysts $\mathrm{Ni}_{x} \mathrm{MoC}-\mathrm{SiO}_{2}$ $(400 / 600)$ were studied using nitrogen porosimetry method. All the samples had an adsorption isotherm corresponding to the structure of a micro-mesoporous material The analysis of results, including the total surface areas determined by Brunauer-Emmett-Teller (BET) method $\mathrm{A}_{\mathrm{BET}}$, the total porous volumes $\mathrm{V}$ and the average pore sizes $\mathrm{D}$, are presented in Table 6.

Table 6. The total surface area $\mathrm{A}_{\mathrm{BET}}$, the average pore size $\mathrm{D}$ and the total pore volume $\mathrm{V}$ for the calcined and reduced $\mathrm{Ni}_{x} \mathrm{MoC}-\mathrm{SiO}_{2}(400 / 600)$ catalysts.

\begin{tabular}{cccc}
\hline Catalyst & $\mathbf{A}_{\text {BET }}, \mathbf{~ m}^{2} / \mathbf{g}$ & $\mathbf{V}, \mathbf{c m}^{3} / \mathbf{g}$ & $\mathbf{D}, \mathbf{n m}$ \\
\hline $\mathrm{Ni}_{0.5} \mathrm{MoC}_{-}-\mathrm{SiO}_{2}(400 / 600)$ & 11.29 & 0.0149 & 5.27 \\
$\mathrm{Ni}_{1} \mathrm{MoC}-\mathrm{SiO}_{2}(400 / 600)$ & 11.35 & 0.0189 & 6.67 \\
$\mathrm{Ni}_{2} \mathrm{MoC}-\mathrm{SiO}_{2}(400 / 600)$ & 27.75 & 0.0307 & 4.42 \\
$\mathrm{Ni}_{4} \mathrm{MoC}-\mathrm{SiO}_{2}(400 / 600)$ & 43.43 & 0.0512 & 4.71 \\
$\mathrm{Ni}_{6} \mathrm{MoC}-\mathrm{SiO}_{2}(400 / 600)$ & 23.17 & 0.0574 & 9.91 \\
\hline
\end{tabular}

According to the data in Table 6, the total surface area $A_{B E T}$ is in the range from 11.29 to $43.43 \mathrm{~m}^{2} / \mathrm{g}$. These values exceed the previous ones obtained for similar catalysts [37], whose maximal surface area was $\mathrm{A}_{\mathrm{BET}}=10 \mathrm{~m}^{2} / \mathrm{g}$ for the system $\mathrm{Ni}_{6} \mathrm{MoC}-\mathrm{SiO}_{2}(400 / 600)$. This difference is most likely due to the influence of ethylene glycol, which is a good complexing agent and leads to an increase in the catalyst surface area. The high value of the catalysts surface area could be connected also with the existence of highly dispersed phases.

It was shown that the average pore diameter varies between 3.92 and $9.91 \mathrm{~nm}$. These sizes characterize the mesoporous adsorbents. The total pore volume $\mathrm{V}_{\text {pore }}$, determined from the maximum nitrogen uptake, increases with the rise of nickel content. This dependence is apparently explained by the high activity of nickel in hydrogenation reactions. In particular, nickel may catalyze the process of carbon removal on the stage of catalyst precursor reduction. Therefore, the introduction of nickel into the catalyst precursor ultimately leads to the release of the pores occupied by carbon. Earlier, Zhao et al. [42] showed that nickel allows improving the porous structure of the molybdenum carbide catalyst. Authors studied the catalysts surface images taken by scanning (SEM) and transmission (TEM) electron microscope. They found that the MoC sample had a dense structure without the pore system, while modification by nickel increases the specific surface area and results in the appearance of a developed pore structure. The data obtained by Zhao et al. [42] have a good agreement with the TEM catalysts characterization obtained in the current work and presented below. As a result, porous 
analysis of carbide catalysts $\mathrm{Ni}_{x} \mathrm{MoC}-\mathrm{SiO}_{2}(400 / 600)$ has shown that the systems are mesoporous materials. The addition of ethylene glycol as a complexing agent and the introduction of nickel take an important place in the formation of their structure.

\subsection{Surface Composition of Ni-Mo Carbide Catalysts}

The relative atomic concentrations of the main elements determined by XPS are given in Table 7. It was found that the systems are multi-phased and heterogeneous. The samples include the components that could be described as molybdenum oxides on $\mathrm{SiO}_{2}$, a mixture of nickel and molybdenum carbides on $\mathrm{SiO}_{2}$, and nickel oxide on $\mathrm{SiO}_{2}$. In contrast to XRD data, oxygen was detected on the surface of catalysts by XPS. This oxygen may belong to Ni or Mo oxide formed after passivation. Nickel content on the surface increases with nickel content in the catalyst. It was found that the Ni/Mo ratio observed by XPS is less than the values of molar ratio $x=N i / M o$ in the catalyst, which indicates that the surface is enriched with molybdenum. The carbon content for $x=4$ and 6 is low, which is in agreement with XRD and CHNS analysis.

Table 7. XPS data and atomic ratio of elements on the surface of the calcined and reduced $\mathrm{Ni}_{x} \mathrm{MoC}-\mathrm{SiO}_{2}$ $(400 / 600)$ catalysts.

\begin{tabular}{cccccc}
\hline Catalyst & $\mathbf{N i} / \mathbf{S i}$ & $\mathbf{M o} / \mathbf{S i}$ & $\mathbf{O} / \mathbf{S i}$ & $\mathbf{C} / \mathbf{S i}$ & $\mathbf{N i} / \mathbf{M o}$ \\
\hline $\mathrm{Ni}_{1} \mathrm{MoC}-\mathrm{SiO}_{2}(400 / 600)$ & 0.87 & 3.04 & 4.84 & 2.02 & 0.29 \\
$\mathrm{Ni}_{2} \mathrm{MoC}-\mathrm{SiO}_{2}(400 / 600)$ & 0.69 & 1.08 & 2.75 & 2.24 & 0.65 \\
$\mathrm{Ni}_{4} \mathrm{MoC}-\mathrm{SiO}_{2}(400 / 600)$ & 0.45 & 0.24 & 1.55 & 0.20 & 1.50 \\
$\mathrm{Ni}_{6} \mathrm{MoC}-\mathrm{SiO}_{2}(400 / 600)$ & 0.77 & 0.18 & 1.54 & 0.34 & 4.56 \\
\hline
\end{tabular}

\subsection{Catalysts Characterization by Transmission Electron Microscopy}

Figure 9 presents TEM images and corresponding patterns of Energy-dispersive X-ray spectroscopy (EDX) for $\mathrm{Ni}_{1} \mathrm{MoC}-\mathrm{SiO}_{2}(400 / 600)$ catalyst. The images are typical for whole series of reduced $\mathrm{Ni}_{x} \mathrm{MoC}-\mathrm{SiO}_{2}(400 / 600)$ systems.
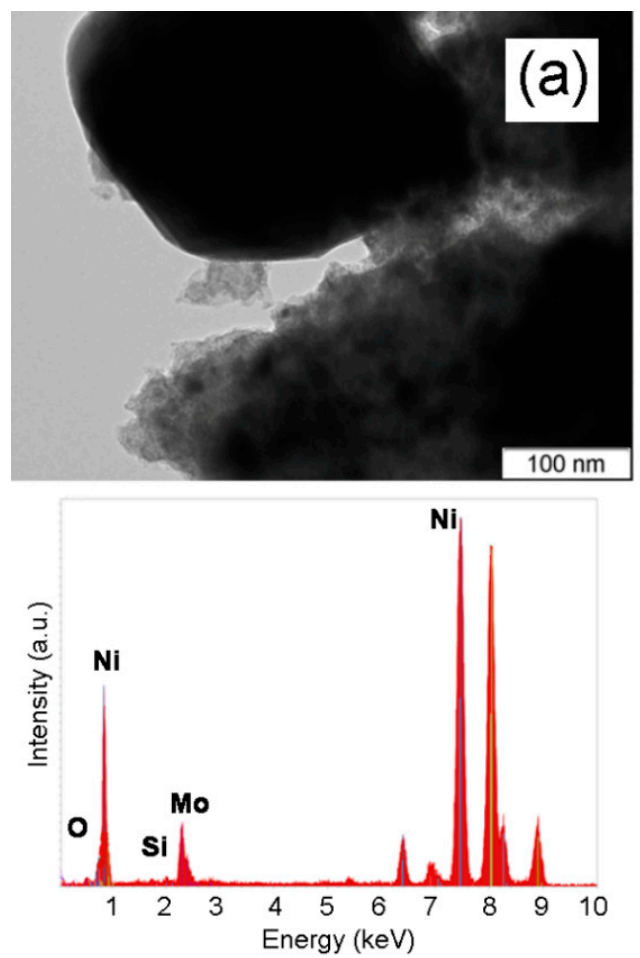
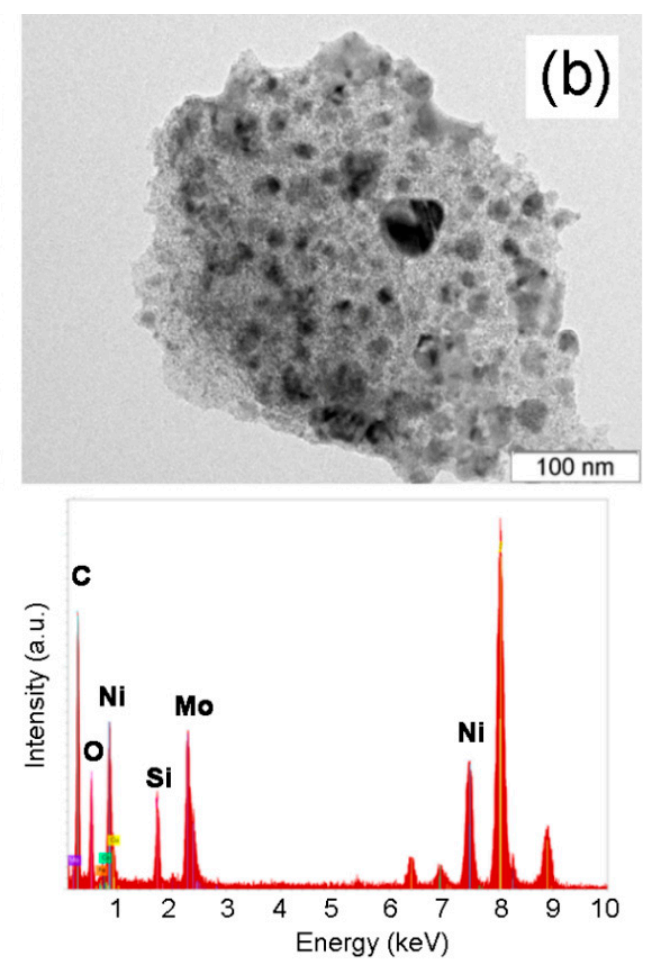

Figure 9. TEM images of the reduced $\mathrm{Ni}_{1} \mathrm{MoC}-\mathrm{SiO}_{2}(400 / 600)$ catalyst with corresponding EDX patterns. 
According to TEM data, there are large particles of Ni-Mo alloy $(400-500 \mathrm{~nm})$ with around $10 \mathrm{wt} \%$ of Mo (Figure 9a). In addition, we detected inclusions of small 1-2 $\mathrm{nm}$ particles of molybdenum carbide in a silica matrix (Figure 9b). The small size of the carbide phase confirms that there are highly dispersion phases in catalysts compound, which cannot be detected by XRD that correlates with the mentioned earlier difference between CHNS and XRD analysis. Herewith, analysis of different TEM images showed, that the appearance of carbon-containing particles decreases with growth in atomic ratio $\mathrm{x}=\mathrm{Ni} / \mathrm{Mo}$ in the catalyst, while small molybdenum oxide inclusions were observed. It indicates that dispersed carbide phase is replacing by oxide phase. It was noted that in most cases $\mathrm{Ni}-\mathrm{Mo}$ alloys particles have significant sizes. It means Ni-Mo phase has low active surface and could barely participate in the sorption and transformation of furfural and its derivatives, but it could be involved in highly efficient spill over of atomic hydrogen from Ni sites to molybdenum carbide or oxide. As shown previously molybdenum oxides have high activity in the hydrogenation of aromatic ring [43], and they could be an active site for the non-selective adsorption of furfural and furfuryl alcohol leading to hydrogenation of furan ring and formation of THFA and 2-MTHF.

\subsection{Kinetics Modeling of Furfural Hydrogenation over Reduced Ni-Mo Carbide Catalysts}

To study the activity and selectivity of the reduced catalysts, the dependences of reagent and products concentrations on the reaction time were studied (Figure 10). As it follows from the kinetic profiles of the reaction, the main products of furfural hydrogenation for the catalysts $\mathrm{Ni}_{0.5} \mathrm{MoC}-\mathrm{SiO}_{2}$ $(400 / 600)$ and $\mathrm{Ni}_{1} \mathrm{MoC}-\mathrm{SiO}_{2}(400 / 600)$ were FA and 2-MF. THFA was detected for the reduced systems $\mathrm{Ni}_{x} \mathrm{MoC}_{-} \mathrm{SiO}_{2}(400 / 600)$ with $x>1$. The formation of 2-MTHF was observed in small amounts up to $6 \mathrm{~mol} \%$ for the $\mathrm{Ni}_{6} \mathrm{MoC}-\mathrm{SiO}_{2}(400 / 600)$ catalyst with a high nickel content. Also, during the reaction, the formation of FHIE and its hydrogenation products was observed, but their total amount was low, and the total content did not exceed $5 \mathrm{~mol} \%$, therefore these compounds were not taken into account in kinetic calculations. As it follows from the graphs in Figure 10, the conversion rate of the feedstock increases with the growth of nickel amount in the catalyst. However, together with the increase in the nickel content, the yield of furan ring hydrogenation products (THFA and 2-MTHF) also increases. An important feature of the reduced systems is the kinetics shift zone, which is observed for catalysts $\mathrm{Ni}_{0.5} \mathrm{MoC}_{-} \mathrm{SiO}_{2}(400 / 600)$ and $\mathrm{Ni}_{1} \mathrm{MoC}-\mathrm{SiO}_{2}(400 / 600)$ after 110 min of reaction. The presence of this zone is reflected by the rapid change in the reaction profile. It is accompanied by a fall and subsequent reduction of the catalyst activity near $110 \mathrm{~min}$. The existence of such a region may be explained by changes in the composition of the catalyst active component during the reaction. 

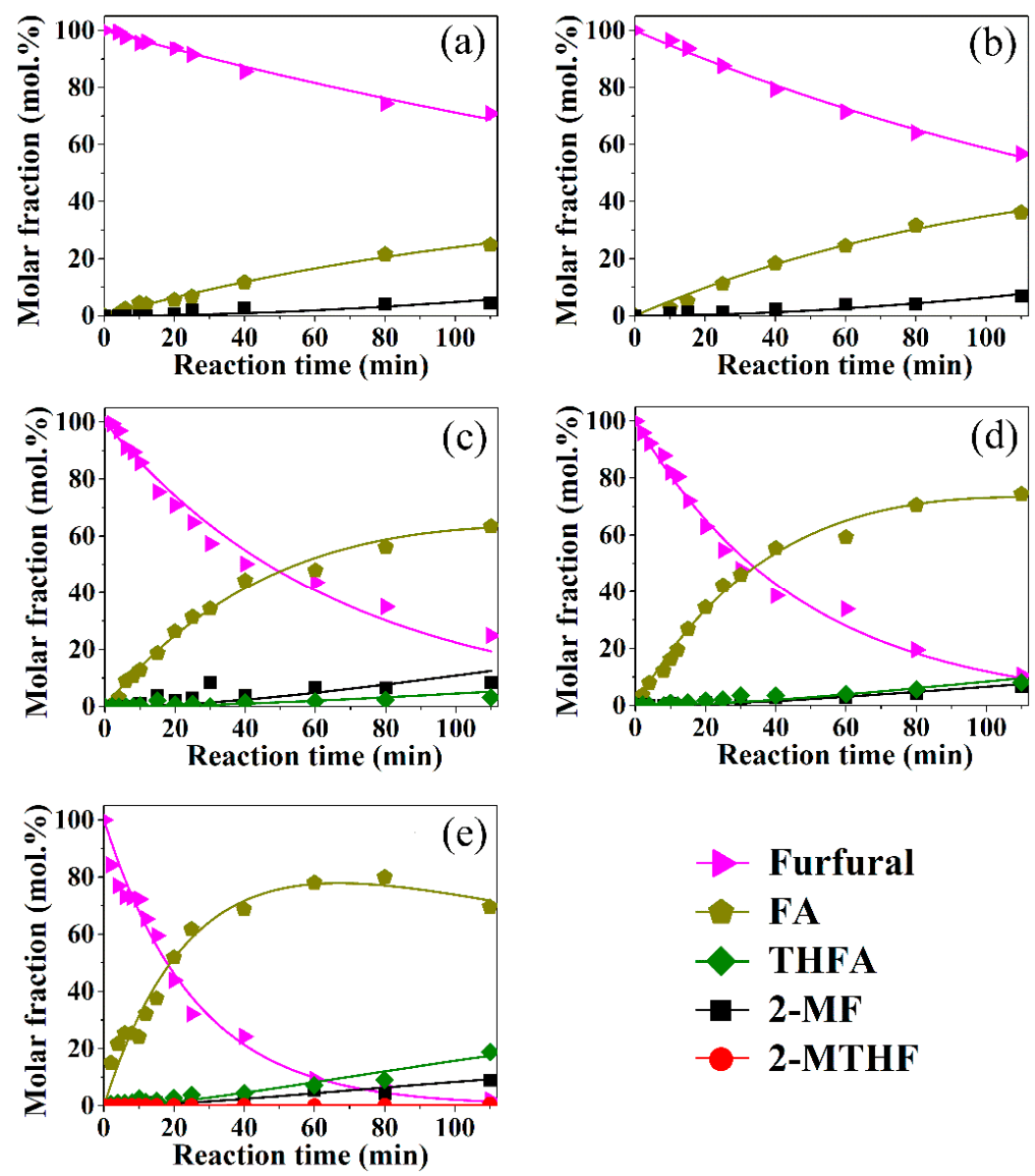

Figure 10. Dependence of reagent and products concentrations on the reaction time for the calcined and reduced $\mathrm{Ni}_{x} \mathrm{MoC}-\mathrm{SiO}_{2}(400 / 600)$ catalysts: (a) $\mathrm{Ni}_{0.5} \mathrm{MoC}-\mathrm{SiO}_{2}(400 / 600)$; (b) $\mathrm{Ni}_{1} \mathrm{MoC}-\mathrm{SiO}_{2}$ (400/600), (c) $\mathrm{Ni}_{2} \mathrm{MoC}-\mathrm{SiO}_{2}$ (400/600); (d) $\mathrm{Ni}_{4} \mathrm{MoC}-\mathrm{SiO}_{2}(400 / 600)$, (e) $\mathrm{Ni}_{6} \mathrm{MoC}-\mathrm{SiO}_{2}(400 / 600)$; symbols-experimental data, lines-calculated data; reaction conditions: $\mathrm{T}=150{ }^{\circ} \mathrm{C}, \mathrm{P}=6.0 \mathrm{MPa}$, $\mathrm{m}_{\text {cat }}=1.000 \mathrm{~g}$, and furfural/isopropanol molar ratio equal to 0.033 .

Based on the reaction products distribution, a furfural hydrogenation scheme was proposed for catalysts $\mathrm{Ni}_{x} \mathrm{MoC}-\mathrm{SiO}_{2}$ (400/600) (Figure 11).

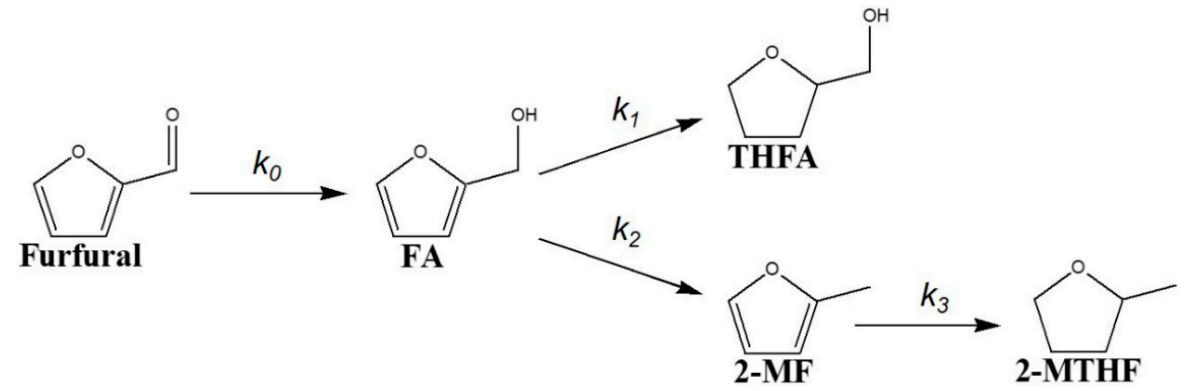

Figure 11. Scheme of furfural hydrogenation over calcined and reduced $\mathrm{Ni}_{x} \mathrm{MoC}-\mathrm{SiO}_{2}(400 / 600)$ catalysts at $\mathrm{T}=150{ }^{\circ} \mathrm{C}, \mathrm{P}=6.0 \mathrm{MPa}, \mathrm{m}_{\mathrm{cat}}=1.000 \mathrm{~g}$, and furfural/isopropanol molar ratio equal to 0.033 .

This scheme includes the route of furfural hydrogenation to FA, which can be converted to 2-MF or THFA. The aromatic ring of 2-MF can be hydrogenated to form 2-MTHF. All kinetic constants $\mathrm{k}_{0}-\mathrm{k}_{3}$ were determined according to the proposed scheme and the reaction products. Since the hydrogen pressure did not change during the experiment, the dependence of the reaction rates on the hydrogen pressure was taken into account in the rate constants. 
The kinetic modelling was based on the proposed scheme of reactions (Figure 11), and calculations were carried out with the use of the following model:

$$
\begin{gathered}
\frac{d C_{i}}{d t}=R_{i} \\
R_{i}=\sum_{m} r_{m} \\
r_{m}=k_{m} C_{m}{ }^{n}
\end{gathered}
$$

where $k_{m}$ is the rate constant, $C_{i}$ and $C_{m}$ are the mole fractions of each component, $R_{i}$ is the reaction rate, and $n$ is the order of the reaction ( $n=1$ for all reactions). An experimental point serves as $t=0$, $C_{i}$ and $C_{m}$ are equal to the mole fractions of the corresponding compounds at the first point.

The set of equations was solved by the numerical integration using the Runge-Kutta method, and kinetic parameters were found by minimizing the sum of squared differences of the estimated and experimental values of the mole fraction of each compound for each experimental point. The minimizing function has the form:

$$
F=\sum_{i} \sum_{j}\left(\frac{C_{i j e x p}-C_{i j c a l c}}{C_{i j \exp }}\right)^{2}
$$

where $j$ is the number of the experimental point; and $i$ is the serial number of the compound from the reaction scheme.

The concentration variations of the reactant and products in the reaction mixture as a function of reaction time and kinetic modelling results are displayed in Figure 10.

For determination of the reactions rate constants, the experimental points to 110 min were taken. This choice is due to the presence of kinetics shift zone for low-nickel catalysts $(x=0.5,1)$, which can be associated with a change in the state of the active component during the reaction. Thus, reaction rate constants for all $\mathrm{Ni}_{x} \mathrm{MoC}_{-} \mathrm{SiO}_{2}(400 / 600)$ catalysts were obtained and their values are listed in Table 8 .

\begin{tabular}{|c|c|c|c|c|}
\hline Catalyst & $k_{0} \cdot 10^{3}, \min ^{-1}$ & $k_{1} \cdot 10^{3}, \min ^{-1}$ & $k_{2} \cdot 10^{3}, \min ^{-1}$ & $k_{3} \cdot 10^{3}, \min ^{-1}$ \\
\hline $\mathrm{Ni}_{0.5} \mathrm{MoC}-\mathrm{SiO}_{2}$ & $3.4 \pm 0.1$ & - & $3.6 \pm 0.7$ & - \\
\hline $\mathrm{Ni}_{1} \mathrm{MoC}-\mathrm{SiO}_{2}$ & $5.3 \pm 0.1$ & - & $3.2 \pm 0.5$ & - \\
\hline $\mathrm{Ni}_{2} \mathrm{MoC}-\mathrm{SiO}_{2}$ & $15 \pm 0.6$ & $1.1 \pm 0.2$ & $2.6 \pm 0.3$ & - \\
\hline $\mathrm{Ni}_{4} \mathrm{MoC}-\mathrm{SiO}_{2}$ & $21 \pm 0.5$ & $1.6 \pm 0.2$ & $1.3 \pm 0.1$ & - \\
\hline $\mathrm{Ni}_{6} \mathrm{MoC}-\mathrm{SiO}_{2}$ & $39 \pm 2$ & $2.4 \pm 0.2$ & $1.3 \pm 0.2$ & $2.4 \pm 0.2$ \\
\hline
\end{tabular}

Table 8. Reaction rate constants of the furfural conversion over calcined and reduced $\mathrm{Ni}_{x} \mathrm{MoC}-\mathrm{SiO}_{2}$ $(400 / 600)$ catalysts at $\mathrm{T}=150{ }^{\circ} \mathrm{C}, \mathrm{P}=6.0 \mathrm{MPa}, \mathrm{m}_{\text {cat }}=1.000 \mathrm{~g}$, and furfural/isopropanol molar ratio equal to 0.033 .

The calculated data demonstrated that, for the reduced catalytic systems, there is a linear increase in the effective rate constants of furfural hydrogenation to FA with an increase in the nickel content in the catalyst (Figure 12). 


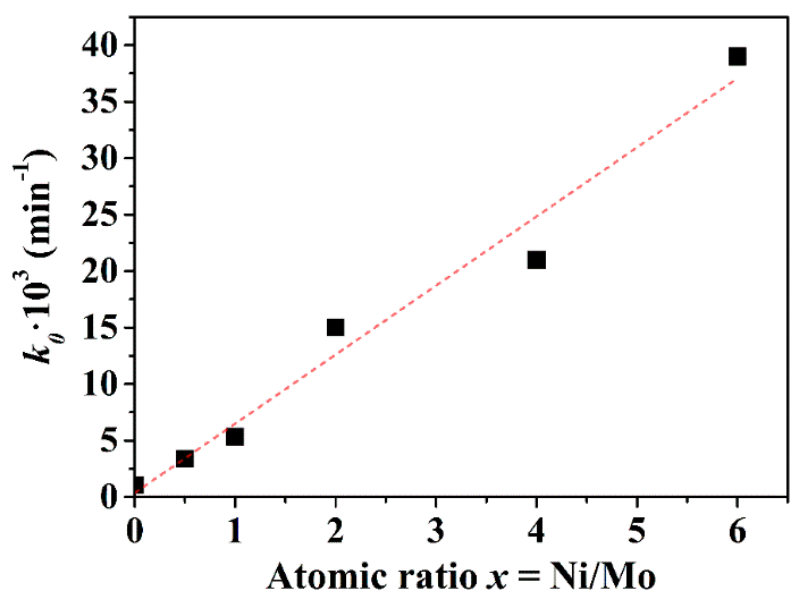

Figure 12. Dependence of the reaction rate constant $k_{0}$ for different calcined and reduced catalysts $\mathrm{Ni}_{x} \mathrm{MoC}-\mathrm{SiO}_{2}(400 / 600)$ and calcined sample $\mathrm{MoC}-\mathrm{SiO}_{2}(700)$ on the atomic ratio $x=\mathrm{Ni} / \mathrm{Mo}$. Reaction conditions: $\mathrm{T}=150{ }^{\circ} \mathrm{C}, \mathrm{P}=6.0 \mathrm{MPa}, \mathrm{m}_{\mathrm{cat}}=1.000 \mathrm{~g}$, and furfural /isopropanol molar ratio equal to 0.033 .

The values of rate constants were used to calculate the selectivity for the formation routes of 2-MF and THFA from FA. This calculation was carried out according to the formulas below. The possibility of 2-MF hydrogenation to 2-MTHF was not taken into account since this route was found only for the $\mathrm{Ni}_{6} \mathrm{MoC}-\mathrm{SiO}_{2}(400 / 600)$ catalyst and was not observed for other systems.

$$
\begin{aligned}
& S_{S e l_{2-M F}}=\frac{k_{2}}{k_{1}+k_{2}} \cdot 100 \% \\
& S e l_{\text {THFA }}=\frac{k_{1}}{k_{1}+k_{2}} \cdot 100 \%
\end{aligned}
$$

Here, $k_{1}$ is the reaction rate constant for hydrogenation of FA to THFA, and $k_{2}$ is the rate constant for hydrogenation of FA to 2-MF.

It was shown that selectivity of 2-MF formation from FA decreases with an increase in the atomic ratio $x=\mathrm{Ni} / \mathrm{Mo}$ (Figure 13).

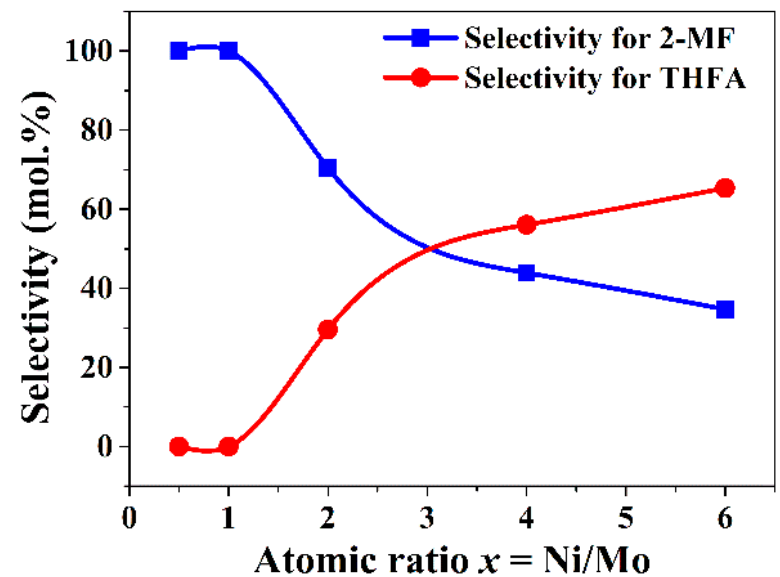

Figure 13. Dependence of selectivity for 2-MF and THFA formation from FA on the atomic ratio $x=\mathrm{Ni} / \mathrm{Mo}$. Reaction conditions: $\mathrm{T}=150{ }^{\circ} \mathrm{C}, \mathrm{P}=6.0 \mathrm{MPa}, \mathrm{m}_{\mathrm{cat}}=1.000 \mathrm{~g}$, and furfural/isopropanol molar ratio equal to 0.033 .

According to Figure 13, the highest selectivity for 2-MF formation is achieved for the catalysts with a low nickel content. The maximum selectivity of ca. $100 \%$ is achieved over $\mathrm{Ni}_{0.5} \mathrm{MoC}-\mathrm{SiO}_{2}$ $(400 / 600)$ and $\mathrm{Ni}_{1} \mathrm{MoC}-\mathrm{SiO}_{2}(400 / 600)$ catalysts. Comparing the selectivity values and the data of 
catalysts surface composition, it can be found that in the $\mathrm{Ni}_{x} \mathrm{MoC}-\mathrm{SiO}_{2}(400 / 600)$ series with $\mathrm{x}=1,2$, 4,6 , an exponential decrease in the selectivity is observed with an increase in nickel content on the catalyst surface (Figure 14).

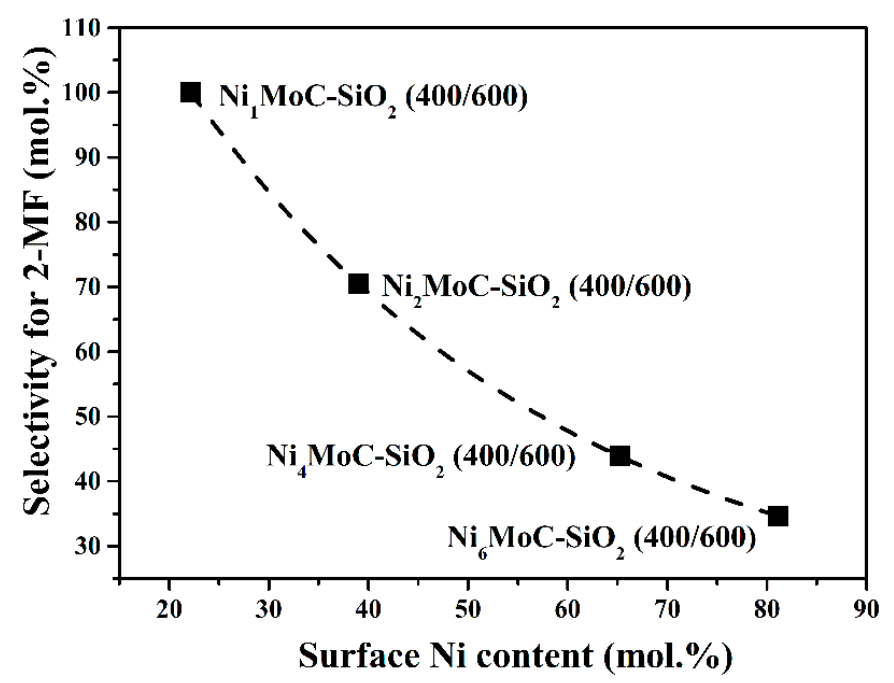

Figure 14. Relation of the selectivity for 2-MF formation from FA with the surface nickel content.

As it follows from Figure 14, the optimal nickel content in the surface layer for efficient 2-MF production does not exceed $22 \%$. At the same time, saturation of the surface with nickel leads to a decrease in the selectivity. In particular, when the Ni quantity in the surface layer achieves $65 \%$, the selectivity of such catalyst does not exceed $44 \%$. It is important to note that the $\mathrm{Ni}_{6} \mathrm{MoC}-\mathrm{SiO}_{2}$ (400/600) sample containing the highest quantity of Ni-Mo alloys (96\% according to XRD) keeps the selectivity for 2-MF equal to $35 \%$. In addition, within the limit of $100 \% \mathrm{Ni}$ content on the catalyst surface, the selectivity remains equal to $28 \%$. As it was mentioned earlier, catalysts with the atomic ratio $\mathrm{x}=\mathrm{Ni} / \mathrm{Mo}$ of 4 and 6 do not actually contain carbide phases. Their main component is a nickel-molybdenum alloy, which promotes the formation of THFA and 2-MTHF. Thus, molybdenum carbide exhibits a high selectivity in the formation of 2-MF.

Probably, molybdenum carbide is responsible for the adsorption of furfural in a conformation which leads to the formation of FA and 2-MF, whereas nickel contributes to the activation of molecular hydrogen. Indeed, Shi et al. [44] performed detailed density functional theory (DFT) and microkinetic calculations to provide a fundamental understanding of the mechanism of furfural hydrogenation over molybdenum carbide surface. They showed that there are five adsorption configurations of furfural on the $\mathrm{Mo}_{2} \mathrm{C}$ surface. The most stable is the cis-furfural absorbed via the $\eta 2(\mathrm{C}=\mathrm{O})$ bonding configuration with the $\mathrm{C}=\mathrm{O}$ bond elongated, and furan ring tilted away from the surface. From this configuration, two competitive pathways are possible, which include $\mathrm{C}-\mathrm{H}$ scission that leads to furan formation, and hydrogenation that results in formation of intermediate product $\mathrm{F}-\mathrm{CH}_{2} \mathrm{O}$, where $\mathrm{F}$ is 2-furanyl radical. She et al. shown that the $\mathrm{C}-\mathrm{O}$ dissociation of $\mathrm{F}-\mathrm{CH}_{2} \mathrm{O}$ into $\mathrm{F}-\mathrm{CH}_{2}+\mathrm{O}$ is more favoured than $\mathrm{F}-\mathrm{CH}_{2} \mathrm{O}$ hydrogenation into furfuryl alcohol both kinetically and thermodynamically. Once $\mathrm{FA}\left(\mathrm{F}-\mathrm{CH}_{2} \mathrm{OH}\right)$ is formed, it can easily go back to $\mathrm{F}-\mathrm{CH}_{2} \mathrm{O}$ under equilibrium condition due to the much low back energy barrier. Therefore, the most favoured surface species are the co-adsorbed $\mathrm{F}-\mathrm{CH}_{2}$ and $\mathrm{O}$, which are used for the formation of 2-methylfuran. Herewith, the pathway of $\mathrm{F}-\mathrm{CH}_{2} \mathrm{O}$ formation occurs when the catalyst surface is covered by hydrogen, especially in the case of $4 \mathrm{H}$ pre-covered surface. On the other hand, it is clearly known that $\mathrm{Ni}$ is a highly reactive catalyst for organic compounds hydrogenation. In the instance, Rodiansono et al. [45] showed that Raney-Ni-clay composite catalysts immediately hydrogenate furfural to THFA through the quiet formation of FA at $120{ }^{\circ} \mathrm{C}$ and $2.0 \mathrm{MPa}$ of $\mathrm{H}_{2}$. Such behavior of $\mathrm{Ni}$ in hydrogenation reaction indicates unselective chemisorption of furfural on the surface by different parts of its structure, both the ring and the $\mathrm{C}=\mathrm{O}$ 
bond. In our case, the samples include Ni-Mo alloy and its activity, apparently, differs from the activity of pure nickel, however, common properties remain the same. Besides, in accordance with TEM analysis, there are large particles of Ni-Mo alloy and highly dispersion molybdenum oxide in catalysts. Therefore, apparently, the Ni-Mo particles participate in hydrogen activation followed by transfer to molybdenum carbide or oxide sites. Molybdenum carbide allow converting furfural to FA and 2-MF, while molybdenum oxide leads to formation of THFA and 2-MTHF.

In order to evaluate the specific catalytic activity, we used results of $\mathrm{CO}$ chemisorption measurements. The specific activity was determined as the initial conversion rate of furfural over one active site. This definition corresponds to the formula:

$$
\mathrm{TOF}=\frac{k_{0} \cdot n_{\text {furfural }}^{0}}{n_{A S}}
$$

where $k_{0}$ is the rate constant of furfural hydrogenation to FA; $n_{\text {furfural }}^{0}$ is the initial amount of furfural equal to 0.0254 moles; and $n_{A S}$ is the number of active sites. The data obtained are listed in Table 9.

Table 9. TOF values for calcined and reduced $\mathrm{Ni}_{x} \mathrm{MoC}-\mathrm{SiO}_{2}(400 / 600)$ catalysts. Reaction conditions: $\mathrm{T}=150{ }^{\circ} \mathrm{C}, \mathrm{P}=6.0 \mathrm{MPa}, \mathrm{m}_{\mathrm{cat}}=1.000 \mathrm{~g}$, and furfural $/$ isopropanol molar ratio equal to 0.033 .

\begin{tabular}{cc}
\hline Catalyst & TOF, s \\
\hline $\mathrm{Ni}_{0.5} \mathrm{MoC}^{\mathbf{1}}-\mathrm{SiO}_{2}$ & $0.016 \pm 0.001$ \\
$\mathrm{Ni}_{1} \mathrm{MoC}-\mathrm{SiO}_{2}$ & $0.035 \pm 0.001$ \\
$\mathrm{Ni}_{2} \mathrm{MoC}-\mathrm{SiO}_{2}$ & $0.097 \pm 0.004$ \\
$\mathrm{Ni}_{4} \mathrm{MoC}-\mathrm{SiO}_{2}$ & $1.11 \pm 0.03$ \\
$\mathrm{Ni}_{6} \mathrm{MoC}-\mathrm{SiO}_{2}$ & $1.39 \pm 0.07$ \\
\hline
\end{tabular}

Analysis of Table 9 shows that the first four samples with the atomic ratio of $x=0.5-2$ have relatively similar values of specific activity. At the same time, the $\mathrm{Ni}_{4} \mathrm{MoC}-\mathrm{SiO}_{2}(400 / 600)$ and $\mathrm{Ni}_{6} \mathrm{MoC}-\mathrm{SiO}_{2}(400 / 600)$ systems are characterized by a significantly higher specific activity up to 1.2-1.4 s $\mathrm{s}^{-1}$, which may be due to a change in the nature of active component or a change in their surface composition, which were discussed earlier.

Remarkably, the specific activity of the carbide catalyst with atomic ratio $x=\mathrm{Ni} / \mathrm{Mo}$ is equal to 0.5 and 1 is comparable with the activity of highly dispersed $\mathrm{Ni}$ supported on $\mathrm{SiO}_{2}$. For instance, the $\mathrm{Ni}_{1} \mathrm{MoC}-\mathrm{SiO}_{2}(400 / 600)$ sample has TOF equal to $0.035 \mathrm{~s}^{-1}$, whereas TOF of the $\mathrm{Ni} / \mathrm{SiO}_{2}$ sample prepared by impregnation method has a maximum of $0.036 \mathrm{~s}^{-1}$ under similar conditions of furfural hydrogenation [46]. Pushkarev et al. [47] reported that Pt nanoparticles supported on MCF-17 mesoporous silica are able to hydrogenate furfural to FA with the selectivity of $68 \%$. Authors tested Pt/MCF-17 samples with different particle sizes in the vapor-phase furfural hydrogenation at atmospheric pressure and $443-513 \mathrm{~K}$. They found that the most selective Pt-based catalysts have specific activity between 0.04 and $0.08 \mathrm{~s}^{-1}$. In our case, systems $\mathrm{Ni}_{4} \mathrm{MoC}-\mathrm{SiO}_{2}(400 / 600)$ and $\mathrm{Ni}_{6} \mathrm{MoC}_{-} \mathrm{SiO}_{2}(400 / 600)$ have the turnover number 1.11 and $1.39 \mathrm{~s}^{-1}$ and their selectivity to FA formation is also high enough. $\mathrm{Cu}$ based catalysts, which were investigated in the liquid-phase furfural hydrogenation, also demonstrated low activity in comparison with carbides. For instance, Villaverde et al. [48] examined the $\mathrm{CuZnAl}, \mathrm{CuMgAl}$ and $\mathrm{Cu}-\mathrm{Cr}$ catalyst, which were synthesized by co-precipitation, in a bath reactor at $110^{\circ} \mathrm{C}$ and pressure 1.0 MPa. In all cases, the selectivity to furfuryl alcohol reached $100 \%$ under the specified conditions. However, the TOF values for $\mathrm{CuMgAl}, \mathrm{Cu}-\mathrm{Cr}$ and $\mathrm{CuZnAl}$ were $0.049,0.022$ and $0.006 \mathrm{~s}^{-1}$, respectively. Bhogeswararao and Srinivas [23] reported about $\mathrm{Pt}$ systems supported on $\gamma-\mathrm{Al}_{2} \mathrm{O}_{3}$, which were tested in gaseous phase furfural hydrogenation at $25{ }^{\circ} \mathrm{C}$ over the pressure range from 2.0 to $6.0 \mathrm{MPa}$. The maximal yield $(91 \%)$ of FA was achieved using the $\mathrm{Pt}(5 \mathrm{wt} \%) / \mathrm{Al}_{2} \mathrm{O}_{3}$ catalyst. Furthermore, the TOF number for this system was $3.06 \mathrm{~s}^{-1}$. This value is much higher than the maximal turnover number detected for Ni-Mo carbides considered in this work. Therefore, a comparison of specific activities of the obtained catalysts with other alternative systems 
shows that Ni-Mo carbides have a rather high efficiency in furfural hydrogenation. Nevertheless, there are catalytic systems with beter catalytic properties, and searching for the ways to increase the activity of carbides remains an actual challenge.

Thus, it is necessary to note that the investigated Ni-Mo catalysts consist of a carbide phase responsible for the selective furfural adsorption and formation of FA and 2-MF, a Ni-Mo alloy involved in the hydrogen activation, and molybdenum oxide responsible for the non-selective furfural adsorption. Therefore, the exact combination of these phases, carbide and metal, allows maintaining high activity and selectivity of the catalyst. Thus, further development of a catalyst with a high content of molybdenum carbide, promoted with a small amount of $\mathrm{Ni}$, can lead to high yields of 2-MF in furfural hydrogenation.

\section{Materials and Methods}

\subsection{Catalyst Preparation}

The precursors of carbide catalysts $\mathrm{Ni}_{x} \mathrm{MoC}-\mathrm{SiO}_{2}$ with the atomic ratio $x=\mathrm{Ni} / \mathrm{Mo}$ equal to $0,0.5,1$, 2,4 , and 6 were prepared by the modified gel-combustion method [42,49] using citric acid and ethylene glycol as the complexation agents. The source of $\mathrm{Mo}$ and Ni was the salts of $\left(\mathrm{NH}_{4}\right)_{6} \mathrm{Mo}_{7} \mathrm{O}_{24} \cdot 4 \mathrm{H}_{2} \mathrm{O}$ (98\%, Reachim) and $\mathrm{Ni}\left(\mathrm{NO}_{3}\right)_{2} \cdot 6 \mathrm{H}_{2} \mathrm{O}(98 \%$, Reachim), respectively.

For the synthesis of catalysts, the corresponding quantities of $\left(\mathrm{NH}_{4}\right)_{6} \mathrm{Mo}_{7} \mathrm{O}_{24} \cdot 4 \mathrm{H}_{2} \mathrm{O}$, $\mathrm{Ni}\left(\mathrm{NO}_{3}\right)_{2} \cdot 6 \mathrm{H}_{2} \mathrm{O}$ and citric acid were dissolved in water under vigorous stirring and heating to $80^{\circ} \mathrm{C}$. Citric acid (CA) was introduced into the mixture with a molar ratio $\mathrm{n}=\mathrm{CA} /(\mathrm{Ni}+\mathrm{Mo})$ equal to 1 . Further, ethylene glycol was added to the solution in the same amount as CA. When the homogeneous solution was obtained, ethyl silicate-32 was added (the amount of $\mathrm{SiO}_{2}$ was $10 \mathrm{wt} \%$ for all samples excluding the amount of carbon). The solution was heated to form a viscous substance. The obtained samples were dried at $100^{\circ} \mathrm{C}$ until the moisture was completely removed.

The dried and ground powder of the precursor was calcined in a quartz reactor under various heat treatment conditions. Catalytic systems $\mathrm{Ni}_{x} \mathrm{MoC}-\mathrm{SiO}_{2}(600)$ and $\mathrm{Ni}_{x} \mathrm{MoC}-\mathrm{SiO}_{2}(700)$ with the atomic ratio $x=\mathrm{Ni} /$ Mo equal to $0,0.5,1,2,6$ were prepared by calcination of the corresponding precursors in the Ar flow at 600 and $700{ }^{\circ} \mathrm{C}$, respectively. The reduced catalysts $\mathrm{Ni}_{x} \mathrm{MoC}_{-} \mathrm{SiO}_{2}(400 / 600)$ with $\mathrm{x}=\mathrm{Ni} / \mathrm{Mo}$ of $0.5,1,2,4$, and 6 were synthesized by calcination in the Ar flow at $400{ }^{\circ} \mathrm{C}$ and following reduction in an $\mathrm{H}_{2}$ atmosphere at $600{ }^{\circ} \mathrm{C}$. Molybdenum carbide without $\mathrm{SiO}_{2}$ was synthesized by calcination at $700{ }^{\circ} \mathrm{C}$ in an inert atmosphere. After every temperature treatment, the samples were cooled to room temperature without air access and passivated by ethanol impregnation.

\subsection{X-ray Diffraction}

The phase composition of Ni-Mo carbide catalysts was investigated by X-ray diffraction analysis. In this study, a D8 Advance X-ray diffractometer (Bruker, Frankfurt, Germany) equipped with a Lynxeye linear detector was used. Monochromatic $\mathrm{CuK} \alpha$ radiation $(\lambda=1.5418 \AA)$ was applied for the analysis. XRD patterns were obtained in the $2 \theta$ range from $15^{\circ}$ to $80^{\circ}$ with a step of $0.05^{\circ}$ and accumulation time of $3-5 \mathrm{~s}$ at each point. The average crystallite size was determined using the Scherrer equation from the integral width of the diffraction lines.

Phase contents were obtained using calibration graphs constructed from the calculated diffraction patterns for $\mathrm{Ni}$, fcc- $\mathrm{MoC}_{1-x}$, and hcp-Mo $\mathrm{M}_{2} \mathrm{C}$. Finally, the Rietveld method [50] was employed to refine the lattice parameters and the phase ratio.

\subsection{Texture Characteristics}

The texture characteristics of the reduced catalysts were examined using the low-temperature nitrogen porosimetry. An automated volumetric adsorption analyser ASAP 2400 (Micromeritics Instrument Corp., Norcross, GA, USA) was used for the analysis. Before recording the nitrogen adsorption 
isotherms, the samples were outgassed at $150{ }^{\circ} \mathrm{C}$ and pressure $0.13 \mathrm{~Pa}$ for $4 \mathrm{~h}$. The experimental data were then used to calculate the surface area $\mathrm{A}_{\mathrm{BET}}$.

\subsection{CO Pulse Chemisorption Measurements}

The number of active sites in the reduced catalysts $\mathrm{Ni}_{x} \mathrm{MoC}-\mathrm{SiO}_{2}(400 / 600)$ were determined by $\mathrm{CO}$ pulse chemisorption measurements using a Chemosorb analyser (Modern Laboratory Equipment, Novosibirsk, Russia). Before analysis, the catalysts were reduced in a stream of $\mathrm{H}_{2}$ at $350{ }^{\circ} \mathrm{C}$. Further, the samples were cooled to $25{ }^{\circ} \mathrm{C}$ into $\mathrm{Ar}$ atmosphere and $\mathrm{CO}$ was pulsed into the reactor until complete sample saturation was observed. The total $\mathrm{CO}$ uptake was used to calculate the number of active sites.

\subsection{Elemental Analysis}

The carbon content in the catalysts before and after reaction was determined using a Vario El III elemental analyser, CHNS version (Elementar, Germany).

\subsection{X-ray Photoelectron Spectroscopy}

The XPS measurements were made using a photoelectron spectrometer (SPECS Surface Nano Analysis $\mathrm{GmbH}$, Berlin, Germany) equipped with a PHOIBOS-150 hemispherical electron energy analyser, a FOCUS-500 X-ray monochromator, and an XR-50 X-ray source with a double Al/Ag anode. The spectrometer was also equipped with a high-pressure cell that makes it possible to heat samples before analysing under gaseous mixtures at pressures up to $0.5 \mathrm{MPa}$. The spectra were recorded using monochromatic $\mathrm{Al} \mathrm{Ka}$ radiation $(\mathrm{hv}=1486.74 \mathrm{eV})$ and a fixed analyser pass energy of $20 \mathrm{eV}$ under ultra-high vacuum conditions. Since $\mathrm{SiO}_{2}$ is included into the catalyst composition, the binding energy scale was calibrated by the internal standard method against the Si2p line of silicon. Relative concentrations of elements were determined from the integral intensities of the core-level spectra using the cross sections according to Scofield [51]. For detailed analysis, the spectra were fitted into several peaks after background subtraction by the Shirley method [52]. The fitting procedure was performed using the CasaXPS software. The shape of lines was approximated by the convolution of Gaussian and Lorentzian functions. Before the analysis, all catalysts were additionally reduced under 1 bar of $\mathrm{H}_{2}$ at $350{ }^{\circ} \mathrm{C}$ for $30 \mathrm{~min}$ in the high-pressure cell.

\subsection{Transmission Electron Microscopy}

The structure and microstructure of powders were examined by high-resolution transmission electron microscopy (HRTEM) on a JEM-2010 electron microscope (JEOL, Tokyo, Japan) at an accelerating voltage of $200 \mathrm{kV}$ and point-to-point resolution of $0.14 \mathrm{~nm}$. The microscope was equipped with a XFlash energy-dispersive X-ray (EDX) spectrometer (Bruker, Ettlingen, Germany) with energy resolution, $125 \mathrm{eV}$. Prior to electron-microscopic examination, the particles were immersed in ethanol and applied to holey carbon substrates (hole diameter near $1 \mu \mathrm{m}$ ) secured on copper grids. The particles were applied using a UZD-1UCh2 ultrasonic processor, which allowed us to achieve a uniform distribution of the particles over the substrate surface. After the particles on the carbon substrate and grid were withdrawn from the ethanol, it was evaporated.

\subsection{Catalytic Activity Tests}

The study of catalysts activity in the furfural hydrogenation was carried out in a batch reactor (Autoclave Engineers, Erie, PA, USA) equipped with a $300 \mathrm{~mL}$ stainless steel reactor. Before the reaction, a pre-ground catalyst ( $1 \mathrm{~g}$ of a fine powder with the size $<0.071 \mathrm{~mm}$ ) was placed in an autoclave and activated in situ in an $\mathrm{H}_{2}$ stream at a temperature of $350{ }^{\circ} \mathrm{C}$ for $60 \mathrm{~min}$. The hydrogen flow was $300 \mathrm{~mL} / \mathrm{min}$. After activation, $60 \mathrm{~mL}$ of $5 \mathrm{wt} \%$ furfural in isopropanol was added into the cooled reactor. The reactor was then sealed, and the mixture was heated to $150{ }^{\circ} \mathrm{C}$ for $40 \mathrm{~min}$. When the 
specified temperature was reached, $6.0 \mathrm{MPa}$ of $\mathrm{H}_{2}$ was fed into the reactor. The onset and endpoint of the reaction corresponded to the times when stirring was turned on and off. The stirring rate was $1800 \mathrm{rpm}$. During the whole process, samples were taken for analysis, and the pressure in the reactor was held at 6.0 MPa. Liquid samples were taken at intervals of 2, 5, 10, 20, 30, and $40 \mathrm{~min}$.

To evaluate carbonization degree of the catalysts, each sample after reaction (the total contact time was 310 min for every experiment) was removed from the chilled reactor and separated from the liquid phase by filtration at room temperature. Further, all the samples were carefully washed with acetone and then dried at $60{ }^{\circ} \mathrm{C}$. The washed and dried catalyst was used for evaluation of the carbon content.

Qualitative analysis of the liquid products was carried out using an Agilent 7000B (Santa Clara, Calif., United States) gas chromatography-mass spectrometer equipped with a triple quadrupole analyser and quartz capillary column CD Wax. NIST.11 database was used to identify the components of the analysed sample. Quantitative analysis of the liquid products of furfural hydrogenation was carried out using an Agilent Technologies GC-7820A (Santa Clara, Calif., United States) gas chromatograph equipped with a flame ionization detector (FID), HP-5 capillary column (stationary phase (5\%-phenyl)-methyl polysiloxane, $30 \mathrm{~m} / 0.32 \mathrm{~mm} \mid 0.25 \mu \mathrm{m}$ ) and CM-WAX capillary column (stationary phase $100 \%$ polyethylene glycol, $30 \mathrm{~m} \mid 0.32 \mathrm{~mm} / 0.25 \mu \mathrm{m}$ ). The temperature program for both columns was: $50^{\circ} \mathrm{C}$ held for $4 \mathrm{~min}, 8^{\circ} \mathrm{C} / \mathrm{min}$ to $240{ }^{\circ} \mathrm{C}$, and holding the final temperature for $3 \mathrm{~min}$. The injector and detector temperatures were 300 and $360^{\circ} \mathrm{C}$, respectively. Argon was used as a carrier gas. The $0.6 \mu \mathrm{L}$ samples of were injected into the gas chromatograph with a chromatographic syringe. The reaction mixture components were identified by retention times, which were determined separately for each component in the calibration. The HP- 5 column was used to identify and separate 2-MF and 2-MTHF. Determination of the other components was carried out using the CM-WAX column.

\section{Conclusions}

The experiments demonstrated that the introduction of stabilizing $\mathrm{SiO}_{2}$ additive into the molybdenum carbide catalyst significantly increases the activity of $\mathrm{MoC}$ during hydrogenation of furfural. It has been shown that the $\mathrm{Ni}_{x} \mathrm{MoC}-\mathrm{SiO}_{2}$ catalysts synthesized by reduction of nickel molybdenum-carbon precursor are able to hydrogenate furfural to 2-methylfuran and furfuryl alcohol with higher yields than the catalysts obtained by calcination in an inert. It has been found that the introduction of nickel significantly increases the specific activity of reduced $\mathrm{Ni}-\mathrm{Mo}$ carbide catalysts in the hydrogenation of furfural from TOF $=0.016 \mathrm{~s}^{-1}$ for $\mathrm{Ni}_{0.5} \mathrm{MoC}-\mathrm{SiO}_{2}$ to $\mathrm{TOF}=1.39 \mathrm{~s}^{-1}$ for $\mathrm{Ni}_{6} \mathrm{MoC}-\mathrm{SiO}_{2}$. It was found that the nickel introduction increases the yields of furfuryl alcohol and products of complete hydrogenation of furan ring-tetrahydrofurfuryl alcohol and 2-methyltetrahydrofuran. The presence of carbide and metal phases in the samples was revealed by XRD analysis. In accordance with the catalytic activity of systems with different Ni content, we found that the metal part represented by Ni-Mo alloy is apparently responsible for the hydrogen activation. At the same time, the carbide part, including such phases as hcp- $-\mathrm{Mo}_{2} \mathrm{C}$, fcc- $-\mathrm{MoC}_{1-x}$ and $\mathrm{Mo}_{3} \mathrm{CNi}_{2}$, participates in loosening of the $\mathrm{C}=\mathrm{O}$ bond of furfural, which leads to the formation of furfuryl alcohol and 2-methylfuran. Molybdenum oxide particles, detected from TEM patterns, participate in non-selective furfural and furfuryl alcohol adsorption leading to the hydrogenation of the aromatic ring. According to the values of reaction rate constants and the proposed reaction scheme, the selectivity of 2-methylfuran formation from furfuryl alcohol was calculated. The maximal selectivity of furfuryl alcohol processing to 2-methylfuran reaches $100 \%$ for the low-nickel systems. As a result of this evaluation, the reduced catalysts $\mathrm{Ni}_{0.5} \mathrm{MoC}-\mathrm{SiO}_{2}$ and $\mathrm{Ni}_{1} \mathrm{MoC}-\mathrm{SiO}_{2}$ can be considered as the most promising catalysts for selective furfural hydrogenation to produce the ecological high-octane additive, 2-methylfuran. Furthermore, it has been demonstrated that the reduced carbide catalysts with the atomic ratio $\mathrm{Ni} / \mathrm{Mo}$ from 1 to 2 can provide the greatest yield of the target products at $150{ }^{\circ} \mathrm{C}$ and hydrogen pressure $6.0 \mathrm{MPa}$, with the maximal yield of furfuryl alcohol reaching $75 \mathrm{~mol} \%$, and the yield of 2-methylfuran reaching $30 \mathrm{~mol} \%$. 
Supplementary Materials: The following are available online at http:/ / www.mdpi.com/2073-4344/8/11/560/s1, Mass Transfer Calculations, Figure S1: The dependence of the lattice parameter on the parameter $\mathrm{x}$ in $\mathrm{Ni}_{1-x} \mathrm{Mo}_{\mathrm{x}}$.

Author Contributions: Conceptualization, V.A.Y.; Formal analysis, A.A.S.; Investigation, I.N.S. and O.A.B.; Visualization, A.A.S.; Writing-original draft, I.N.S.; Writing—review \& editing, V.A.Y.

Funding: This research was funded by the Ministry of Science and Higher Education of the Russian Federation: project No. 14.575.21.0171, identification number of the project RFMEFI57517X0171, title "Development of methods for processing the products of non-food plant raw materials conversion into furanic high-octane additives for motor fuels and into other high-value chemical products".

Acknowledgments: The authors express gratitude to Sergei G. Zavarukhin for carrying out the mathematical calculations and participation in the kinetic modeling. We thank Andrey A. Saraev for carrying out XPS analysis and Evgeny Yu. Gerasimov for making TEM analysis.

Conflicts of Interest: The authors declare no conflict of interest.

\section{References}

1. Mariscal, R.; Maireles-Torres, P.; Ojeda, M.; Sadaba, I.; Lopez Granados, M. Furfural: A renewable and versatile platform molecule for the synthesis of chemicals and fuels. Energy Environ. Sci. 2016, 9, 1144-1189. [CrossRef]

2. Li, X.; Jia, P.; Wang, T. Furfural: A Promising Platform Compound for Sustainable Production of C4 and C5 Chemicals. ACS Catal. 2016, 6, 7621-7640. [CrossRef]

3. Dashtban, M.; Gilbert, A.; Fatehi, P. Production of furfural: Overview and challenges. J. Sci. Technol. Forest. Prod. Process. 2012, 2, 44-53.

4. Dutta, S.; De, S.; Saha, B.; Alam, M.I. Advances in conversion of hemicellulosic biomass to furfural and upgrading to biofuels. Catal. Sci. Technol. 2012, 2, 2025-2036. [CrossRef]

5. Hoydonckx, H.E.; Van Rhijn, W.M.; Van Rhijn, W.; De Vos, D.E.; Jacobs, P.A. Furfural and Derivatives. In Ullmann's Encyclopedia of Industrial Chemistry; Wiley-VCH Verlag GmbH \& Co. KGaA: Weinheim, Germany, 2007.

6. Barr, J.B.; Wallon, S.B. The chemistry of furfuryl alcohol resins. J. Appl. Polym. Sci. 2003, 15, 1079-1090. [CrossRef]

7. Rasina, D.; Lombi, A.; Santoro, S.; Ferlin, F.; Vaccaro, L. Searching for novel reusable biomass-derived solvents: Furfuryl alcohol/water azeotrope as a medium for waste-minimised copper-catalysed azide-alkyne cycloaddition. Green Chem. 2016, 18, 6380-6386. [CrossRef]

8. Kottke, R. Furan derivatives. In Kirk-Othmer Encyclopedia of Chemical Technology; John Wiley \& Sons, Inc.: Hoboken, NJ, USA, 2000.

9. Bayan, S.; Beati, E. Furfural and its derivatives as motor fuels. Chim. Ind. 1941, 23, 432-434.

10. Wang, C.; Xu, H.; Daniel, R.; Ghafourian, A.; Herreros, J.M.; Shuai, S.; Ma, X. Combustion characteristics and emissions of 2-methylfuran compared to 2,5-dimethylfuran, gasoline and ethanol in a DISI engine. Fuel 2013, 103, 200-211. [CrossRef]

11. Corma, A.; de la Torre, O.; Renz, M. Production of high quality diesel from cellulose and hemicellulose by the Sylvan process: Catalysts and process variables. Energy Environ. Sci. 2012, 5, 6328-6344. [CrossRef]

12. Balakrishnan, M.; Sacia Eric, R.; Bell Alexis, T. Selective Hydrogenation of Furan-Containing Condensation Products as a Source of Biomass-Derived Diesel Additives. ChemSusChem 2014, 7, 2796-2800. [CrossRef] [PubMed]

13. Lange, J.P.; van der Heide, E.; van Buijtenen, J.; Price, R. Furfural—A Promising Platform for Lignocellulosic Biofuels. ChemSusChem 2011, 5, 150-166. [CrossRef] [PubMed]

14. Wojcik, B.H. Catalytic Hydrogenation of Furan Compounds. Ind. Eng. Chem. 1948, 40, 210-216. [CrossRef]

15. Burnett, L.W.; Johns, I.B.; Holdren, R.F.; Hixon, R.M. Production of 2-Methylfuran by Vapor-Phase Hydrogenation of Furfural. Ind. Eng. Chem. 1948, 40, 502-505. [CrossRef]

16. Holdren, R.F. Manufacture of Methylfuran. U.S. Patent 2,445,714, 20 July 1948.

17. Rao, R.; Dandekar, A.; Baker, R.T.K.; Vannice, M.A. Properties of Copper Chromite Catalysts in Hydrogenation Reactions. J. Catal. 1997, 171, 406-419. [CrossRef]

18. Liu, D.; Zemlyanov, D.; Wu, T.; Lobo-Lapidus, R.J.; Dumesic, J.A.; Miller, J.T.; Marshall, C.L. Deactivation mechanistic studies of copper chromite catalyst for selective hydrogenation of 2-furfuraldehyde. J. Catal. 2013, 299, 336-345. [CrossRef] 
19. Yan, K.; Liu, Y.; Lu, Y.; Chai, J.; Sun, L. Catalytic application of layered double hydroxide-derived catalysts for the conversion of biomass-derived molecules. Catal. Sci. Technol. 2017, 7, 1622-1645. [CrossRef]

20. Yan, K.; Chen, A. Efficient hydrogenation of biomass-derived furfural and levulinic acid on the facilely synthesized noble-metal-free Cu-Cr catalyst. Energy 2013, 58, 357-363. [CrossRef]

21. Iqbal, S.; Liu, X.; Aldosari, O.F.; Miedziak, P.J.; Edwards, J.K.; Brett, G.L.; Akram, A.; King, G.M.; Davies, T.E.; Morgan, D.J.; et al. Conversion of furfuryl alcohol into 2-methylfuran at room temperature using $\mathrm{Pd} / \mathrm{TiO}_{2}$ catalyst. Catal. Sci. Technol. 2014, 4, 2280-2286. [CrossRef]

22. Vetere, V.; Merlo, A.B.; Ruggera, J.F.; Casella, M.L. Transition metal-based bimetallic catalysts for the chemoselective hydrogenation of furfuraldehyde. J. Braz. Chem. Soc. 2010, 21, 914-920. [CrossRef]

23. Bhogeswararao, S.; Srinivas, D. Catalytic conversion of furfural to industrial chemicals over supported $\mathrm{Pt}$ and Pd catalysts. J. Catal. 2015, 327, 65-77. [CrossRef]

24. Hronec, M.; Fulajtarová, K.; Liptaj, T. Effect of catalyst and solvent on the furan ring rearrangement to cyclopentanone. Appl. Catal. A Gen. 2012, 437-438, 104-111. [CrossRef]

25. Patel, M.A.; Baldanza, M.A.S.; Teixeira da Silva, V.; Bridgwater, A.V. In situ catalytic upgrading of bio-oil using supported molybdenum carbide. Appl. Catal. A Gen. 2013, 458, 48-54. [CrossRef]

26. Wang, F.; Xu, J.; Jiang, J.; Liu, P.; Li, F.; Ye, J.; Zhou, M. Hydrotreatment of vegetable oil for green diesel over activated carbon supported molybdenum carbide catalyst. Fuel 2018, 216, 738-746. [CrossRef]

27. Cai, Z.; Wang, F.; Zhang, X.; Ahishakiye, R.; Xie, Y.; Shen, Y. Selective hydrodeoxygenation of guaiacol to phenolics over activated carbon supported molybdenum catalysts. Mol. Catal. 2017, 441, 28-34. [CrossRef]

28. Chen, C.-J.; Lee, W.-S.; Bhan, A. Mo2C catalyzed vapor phase hydrodeoxygenation of lignin-derived phenolic compound mixtures to aromatics under ambient pressure. Appl. Catal. A Gen. 2016, 510, 42-48. [CrossRef]

29. Xiong, K.; Lee, W.S.; Bhan, A.; Chen, J.G. Molybdenum carbide as a highly selective deoxygenation catalyst for converting furfural to 2-methylfuran. ChemSusChem 2014, 7, 2146-2149. [CrossRef] [PubMed]

30. Xiong, K.; Yu, W.; Chen, J.G. Selective deoxygenation of aldehydes and alcohols on molybdenum carbide (Mo2C) surfaces. Appl. Surf. Sci. 2014, 323, 88-95. [CrossRef]

31. Boullosa-Eiras, S.; Lødeng, R.; Bergem, H.; Stöcker, M.; Hannevold, L.; Blekkan, E.A. Catalytic hydrodeoxygenation (HDO) of phenol over supported molybdenum carbide, nitride, phosphide and oxide catalysts. Catal. Today 2014, 223, 44-53. [CrossRef]

32. Lee, W.-S.; Wang, Z.; Zheng, W.; Vlachos, D.G.; Bhan, A. Vapor phase hydrodeoxygenation of furfural to 2-methylfuran on molybdenum carbide catalysts. Catal. Sci. Technol. 2014, 4, 2340-2352. [CrossRef]

33. Ma, R.; Cui, K.; Yang, L.; Ma, X.; Li, Y. Selective catalytic conversion of guaiacol to phenols over a molybdenum carbide catalyst. Chem. Commun. 2015, 51, 10299-10301. [CrossRef] [PubMed]

34. Dhandapani, B.; St. Clair, T.; Oyama, S.T. Simultaneous hydrodesulfurization, hydrodeoxygenation, and hydrogenation with molybdenum carbide. Appl. Catal. A Gen. 1998, 168, 219-228. [CrossRef]

35. Wang, Y.-Y.; Ling, L.-L.; Jiang, H. Selective hydrogenation of lignin to produce chemical commodities by using a biochar supported Ni-Mo2C catalyst obtained from biomass. Green Chem. 2016, 18, 4032-4041. [CrossRef]

36. Hartline, A.G.; Campbell, J.A.; Magel, T.T. Process for Reclaiming Cemented Metal Carbide. U.S. Patent 3,953,194 (A), 27 April 1976.

37. Smirnov, A.A.; Geng, Z.; Khromova, S.A.; Zavarukhin, S.G.; Bulavchenko, O.A.; Saraev, A.A.; Kaichev, V.V.; Ermakov, D.Y.; Yakovlev, V.A. Nickel molybdenum carbides: Synthesis, characterization, and catalytic activity in hydrodeoxygenation of anisole and ethyl caprate. J. Catal. 2017, 354, 61-77. [CrossRef]

38. Khromova, S.A.; Bykova, M.V.; Bulavchenko, O.A.; Ermakov, D.Y.; Saraev, A.A.; Kaichev, V.V.; Venderbosch, R.H.; Yakovlev, V.A. Furfural Hydrogenation to Furfuryl Alcohol over Bimetallic Ni-Cu Sol-Gel Catalyst: A Model Reaction for Conversion of Oxygenates in Pyrolysis Liquids. Top. Catal. 2016, 59, 1413-1423. [CrossRef]

39. Capeletti, M.A.R.; Balzano, L.; de la Puente, G.; Laborde, M.; Sedran, U. Synthesis of acetal (1,1-diethoxyethane) from ethanol and acetaldehyde over acidic catalysts. Appl. Catal. A Gen. 2000, 198, L1-L4. [CrossRef]

40. Bej, S.K.; Bennett, C.A.; Thompson, L.T. Acid and base characteristics of molybdenum carbide catalysts. Appl. Catal. A Gen. 2003, 250, 197-208. [CrossRef]

41. Vitale, G.; Frauwallner, M.L.; Scott, C.E.; Pereira-Almao, P. Preparation and characterization of low-temperature nano-crystalline cubic molybdenum carbides and insights on their structures. Appl. Catal. A Gen. 2011, 408, 178-186. [CrossRef] 
42. Zhao, L.; Fang, K.; Jiang, D.; Li, D.; Sun, Y. Sol-gel derived Ni-Mo bimetallic carbide catalysts and their performance for CO hydrogenation. Catal. Today 2010, 158, 490-495. [CrossRef]

43. Smirnov, A.A.; Khromova, S.A.; Ermakov, D.Y.; Bulavchenko, O.A.; Saraev, A.A.; Aleksandrov, P.V.; Kaichev, V.V.; Yakovlev, V.A. The composition of Ni-Mo phases obtained by $\mathrm{NiMoO}_{x}-\mathrm{SiO}_{2}$ reduction and their catalytic properties in anisole hydrogenation. Appl. Catal. A Gen. 2016, 514, 224-234. [CrossRef]

44. Shi, Y.; Yang, Y.; Li, Y.-W.; Jiao, H. Mechanisms of Mo2C(101)-Catalyzed Furfural Selective Hydrodeoxygenation to 2-Methylfuran from Computation. ACS Catal. 2016, 6, 6790-6803. [CrossRef]

45. Rodiansono, R.; Hara, T.; Shimazu, S. Total hydrogenation of biomass-derived furfural over raney nickel-clay nanocomposite catalysts. Indones. J. Chem. 2013, 13, 101-107. [CrossRef]

46. Nakagawa, Y.; Nakazawa, H.; Watanabe, H.; Tomishige, K. Total Hydrogenation of Furfural over a Silica-Supported Nickel Catalyst Prepared by the Reduction of a Nickel Nitrate Precursor. ChemCatChem 2012, 4, 1791-1797. [CrossRef]

47. Pushkarev, V.V.; Musselwhite, N.; An, K.; Alayoglu, S.; Somorjai, G.A. High structure sensitivity of vapor-phase furfural decarbonylation/hydrogenation reaction network as a function of size and shape of $\mathrm{Pt}$ nanoparticles. Nano Lett. 2012, 12, 5196-5201. [CrossRef] [PubMed]

48. Villaverde, M.M.; Bertero, N.M.; Garetto, T.F.; Marchi, A.J. Selective liquid-phase hydrogenation of furfural to furfuryl alcohol over Cu-based catalysts. Catal. Today 2013, 213, 87-92. [CrossRef]

49. Stux, A.M.; Laberty-Robert, C.; Swider-Lyons, K.E. Pechini synthesis and characterization of molybdenum carbide and nickel molybdenum carbide. J. Solid State Chem. 2008, 181, 2741-2747. [CrossRef]

50. Rietveld, H. A profile refinement method for nuclear and magnetic structures. J. Appl. Crystallogr. 1969, 2, 65-71. [CrossRef]

51. Scofield, J.H. Hartree-Slater subshell photoionization cross-sections at 1254 and 1487 eV. J. Electron Spectrosc. Relat. Phenom. 1976, 8, 129-137. [CrossRef]

52. Shirley, D.A. High-resolution X-ray photoemission spectrum of the valence bands of gold. Phys. Rev. B 1972, 5, 4709. [CrossRef]

(C) 2018 by the authors. Licensee MDPI, Basel, Switzerland. This article is an open access article distributed under the terms and conditions of the Creative Commons Attribution (CC BY) license (http:/ / creativecommons.org/licenses/by/4.0/). 